\title{
Using local second gradient model and shear strain localisation to model the excavation damaged zone in unsaturated claystone
}

\author{
Benoît Pardoen* · Séverine Levasseur · Frédéric Collin
}

Received: date / Accepted: date

\begin{abstract}
The drilling of galleries induces damage propagation in the surrounding medium and creates, around them, the Excavation Damaged Zone, EDZ. The prediction of the extension and fracture structure of this zone remains a major issue especially in the context of underground nuclear waste storage. Experimental studies on geomaterials indicate that localised deformation in shear band mode usually appears prior to fractures. Thus, the excavation damaged zone can be modelled by considering the development of shear strain localisation bands. In the classical finite element framework, strain localisation suffers of a mesh-dependency problem. Therefore, an enhanced model with a regularisation method is required to correctly model the strain localisation behaviour. Among the existing methods, we choose the coupled local second gradient model. We extend it to unsaturated conditions and we include the solid grain compressibility. Furthermore, air ventilation inside underground galleries engenders a rock-atmosphere interaction that could influence the damaged zone. This interaction has to be investigated in order to predict the damaged zone behaviour. Finally, a hydro-mechanical modelling of a gallery excavation in claystone is presented and leads to a fairly good representation of the EDZ. The main objectives of this study are to model the fractures by considering shear strain localisation bands and to investigate if an isotropic model accurately reproduces the in situ measurements. The numerical results provide information about the damaged zone extension, structure and behaviour that are in very good agreement with in situ measurements and observations. For instance, the strain localisation bands develop in chevron pat-

B. Pardoen* S S. Levasseur · F. Collin

Université de Liège, Département ArGEnCo, Chemin des Chevreuils 1, 4000 Liège, Belgium

Tel.: +32-4-3662033

E-mail: b.pardoen@ulg.ac.be

${ }^{*}$ FRIA, F.R.S.-FNRS scholarship holder
\end{abstract}

tern during the excavation and rock desaturation is observed close to the gallery due to air ventilation.

Keywords Numerical modelling · Fracturing · Excavation damaged zone - Strain localisation - Unsaturated soil · Gallery ventilation

\section{List of symbols}

General notations

$a^{t} \quad$ Current configuration of quantity $a$ at a given time $t$

$\dot{a} \quad$ Time variation of quantity $a$

$d a \quad$ Time variation of quantity $a$ between two given times for iterative procedures

$a^{*} \quad$ Virtual quantity $a$

Greek letters

$\alpha \quad$ Deviatoric strain increment

$\beta_{c} \quad$ Cohesion parameter for suction influence

$\beta_{E} \quad$ Young's modulus parameter for suction influence

$\Gamma \quad$ Porous material boundary

$\Gamma_{\sigma} \quad$ Part of the porous material boundary on which $\bar{t}_{i}$ and $\bar{T}_{i}$ are applied

$\Gamma_{q} \quad$ Part of the porous material boundary on which $\bar{q}$ is prescribed

$\delta_{i j} \quad$ Kronecker symbol

$\Delta_{R / S / W} \quad$ Non-equilibrium forces of balance equations for iterative procedures

$\varepsilon_{i j} \quad$ Total strain field

$\varepsilon_{i j}^{p} \quad$ Plastic strain field

$\hat{\varepsilon}_{i j} \quad$ Deviatoric total strain field

$\hat{\varepsilon}_{i j}^{p} \quad$ Deviatoric plastic strain field

$\varepsilon_{v} \quad$ Volumetric strain 
$\varepsilon_{e q} \quad$ Von Mises' equivalent deviatoric total strain (total deviatoric strain)

$\varepsilon_{e q}^{p} \quad$ Von Mises' equivalent deviatoric plastic strain

$\theta \quad$ Tangential direction

$\lambda_{i j} \quad$ Lagrange multipliers field

$\mu_{w} \quad$ Water dynamic viscosity

$v \quad$ Drained Poisson's ratio

$\rho \quad$ Density

$\rho_{s} \quad$ Solid grain density

$\rho_{w} \quad$ Water density

$\sigma_{i j} \quad$ Cauchy total stress field

$\sigma_{i j}^{\prime} \quad$ Bishop's effective stress field

$\hat{\sigma}_{i j} \quad$ Deviatoric stress field

$\sigma^{\prime} \quad$ Bishop's mean effective stress

$\sigma_{x / y / z, 0} \quad$ Initial principal total stresses

$\Sigma_{i j k} \quad$ Double stress dual of the virtual micro second gradient field

$\tilde{\Sigma}_{i j k} \quad$ Jaumann double stress rate

$\tau_{i j} \quad$ Additional stress field associated to the microstructure (microstress)

$v_{i j} \quad$ Microkinematic gradient field

$\phi_{c} \quad$ Compression friction angle

$\phi_{c, 0} \quad$ Initial compression friction angle

$1 / \chi_{w} \quad$ Water compressibility

$\psi \quad$ Dilatancy angle

$\omega_{i j} \quad$ Spin tensor

$\Omega \quad$ Porous material volume $\phi_{c, f} \quad$ Final compression friction angle

$\begin{array}{ll}M_{w} & \text { Water mass } \\ m_{w, i} & \text { Water mass flow } \\ n & \text { Porosity } \\ N & \text { van Genuchten coefficient } \\ p_{c} & \text { Capillary pressure (matric suction) } \\ p_{g} & \text { Gas pressure } \\ P_{r} & \text { van Genuchten air entry pressure } \\ p_{v} & \text { Partial pressure of water vapour } \\ p_{v, 0} & \text { Pressure of saturated water vapour } \\ p_{w} & \text { Pore water pressure } \\ q & \text { Deviatoric stress } \\ \bar{q} & \text { Input water mass per unit area } \\ Q & \text { Water sink term } \\ q_{w, i} & \text { Average speed of water relative to the solid grains } \\ R & \text { Gas constant } \\ R_{c} & \text { Uniaxial compression strength } \\ R_{c, s a t} & \text { Saturated uniaxial compression strength } \\ R H & \text { Air relative humidity } \\ S_{m a x} & \text { Maximum water degree of saturation } \\ S_{r e s} & \text { Residual water degree of saturation } \\ S_{r, w} & \text { Water degree of saturation } \\ T & \text { Absolute temperature } \\ \bar{t}_{i} & \text { Classical external traction force per unit area } \\ \bar{T}_{i} & \text { Additional external double force per unit area } \\ u_{i} & \text { Displacement field } \\ u_{r} & \text { Radial displacement } \\ u_{\perp, i} & \text { Normal vector of the displacement field } \\ W_{i n t} & \text { Internal work } \\ W_{e x t} & \text { External work } \\ & \end{array}$

Roman letters

$I_{\sigma} \quad$ First stress invariant

$I I_{\hat{\sigma}} \quad$ Second deviatoric stress invariant

$b \quad$ Biot's coefficient

$B_{\phi} \quad$ Friction angle hardening coefficient

$B_{c} \quad$ Cohesion softening coefficient

$c \quad$ Cohesion

$c_{0} \quad$ Initial saturated cohesion

$c_{f} \quad$ Final saturated cohesion

$c_{\text {sat }} \quad$ Saturated cohesion

$D \quad$ Second gradient elastic modulus

$D u_{i} \quad$ Normal derivative of the displacement field

E Drained Young's modulus

$E_{\text {sat }} \quad$ Saturated Young's modulus

$F_{i j} \quad$ Macrodeformation gradient field

$h_{i j k} \quad$ Micro second gradient field

$K \quad$ Drained bulk modulus of the poroelastic material

$k_{i j} \quad$ Intrinsic water permeability tensor

$k_{r, w} \quad$ Relative water permeability

$K_{S} \quad$ Isotropic bulk modulus of the solid grains

$m \quad$ Yield surface parameter

$M \quad$ van Genuchten coefficient

$M_{v} \quad$ Molar mass of water vapour

\section{Introduction}

The currently considered solution for long-term management of radioactive waste is the repository in deep geological media which provide satisfactory confining properties. Due to their low permeability, different formations can be used as natural barrier to isolate long-lived radioactive waste with high and medium activity. To investigate the feasibility of a safe repository in these geological media, many Underground Research Laboratories, URL, are developed around the world (Kickmaier and McKinley 1997), for instance in argilaceous (Félix et al 1996; Delay et al 2007; Neerdael and Boyazis 1997; Croisé et al 2004), granite (Bäckblom 1991; Gens et al 1998) and salt formations (Langer 1999; Behlau and Mingerzahn 2001).

At repository scale, the drilling of galleries, which compose underground structures for radioactive waste repository and URL, induces stress redistribution that triggers damage and cracks propagation. This generates the development of the Excavation Damaged Zone, EDZ, which is characterised by modified rock properties. These properties modifications, such as permeability increase (Bossart et al 2002), could 
alter the safety function of the rock in the case of nuclear waste repository. The damaged zone can also be influenced by rock-atmosphere interactions due to air ventilation usually performed inside the galleries. Consequently, it is obvious that understanding and predicting the behaviour of the excavation damaged zone is nowadays a major issue (Blümling et al 2007).

Experimental studies, at small and large scale, highlight that the damage around underground galleries develops as cracks and that strain localisation in shear band mode can lead to fractures (see section 2.1). In the classical finite element framework, the strain localisation is mesh-dependent and thus an enhanced model is needed to correctly represent the localisation behaviour (Bésuelle et al 2006). To this goal, we choose to use the coupled local second gradient model which includes an enrichment of the continuum with microstructure effects (Chambon et al 2001). We extend the coupled problem to unsaturated conditions and include the compressibility of the solid grains through the Biot's coefficient (see sections 3 and 4).

In this particular study, we consider the Callovo-Oxfordian claystone as host material. This argillaceous rock surrounds the underground research laboratory of the French national radioactive waste management agency, Andra, which is located in Bure, Meuse/Haute-Marne, France (Andra 2005). Many in situ observations and measurements of fractures are conducted in the vicinity of this laboratory. To characterise the damaged zone, we are especially interested in the fractures that are located at the front and around experimental galleries. These fractures are described in Armand et al (2014) and Cruchaudet et al (2010b). Their measurements provide the extension of the EDZ and a description of the fracturing pattern including the type of fractures.

Firstly, we define the excavation damaged zone by focusing on evidences of the mechanical fracturing and soilatmosphere interaction (see section 2). Then, the coupled local second gradient model and the other constitutive models are detailed under unsaturated conditions (see sections 3 and 4). Finally, we numerically model a gallery excavation in order to reproduce the development of the EDZ at nuclear waste repository scale (see sections 5 and 6). Shear strain localisation in bands mode represents the fractures in the damaged zone and the ventilation process is modelled to investigate the possible desaturation of the rock. Particular attention is paid to the prediction of the EDZ extension and fracturing structure as well as to the influence of the gallery ventilation.

Many studies on claystone have been performed with two-dimensional isotropic models. Our purpose is to investigate if this type of model can reproduce the in situ observations and measurements by incorporating the fracture modelling with strain localisation. This type of modelling, especially at large repository scale and including solid grain compressibility as well as rock desaturation, has not been widely performed recently. Therefore, it is a major novelty of this study. The unsaturated condition and the compressibility of the material are incorporated in the second gradient model developed by Collin et al (2006) for incompressible saturated multiphasic medium. These novelties are implemented in the non-linear finite element code Lagamine developed at the University of Liège (Charlier 1987; Collin 2003), which is used to perform the modelling.

\section{Fracturing evidences}

\subsection{Mechanical fracturing and excavation damaged zone}

Stress redistribution in materials engenders damage that can be either diffused or localised and can induce fracturing. When the damage threshold is reached, micro-cracks initiate, then accumulate, propagate (distributed damage) and can lead to the onset of macro-cracks (interconnected fractures). Different modes of fractures exist : opening or tensile fractures, shear fractures and mixed-mode fractures, which is a combination of the two previous modes (Jenq and Shah 1988). Geomaterials such as rocks and soils have low tensile strength, thus tensile rupture is arduous to characterise. On the other hand compression laboratory tests allow to characterise the compression material behaviour until the rupture.

At small scale, numerous experimental studies performed on geomaterials are devoted to strain localisation which corresponds to the accumulation of large shear strain in limited zones (Vardoulakis et al 1978; Finno et al 1996; Finno et al 1997; Han and Drescher 1993; Alshibli et al 2003). They are mainly performed on biaxial apparatus and they involve special techniques, such as X-ray microtomography, three dimensional digital image correlation (Lenoir et al 2007) and stereophotogrammetry (Desrues and Viggiani 2004), to study the evolution of the strain localisation processes. These experimental studies indicate that strain localisation in shear band mode is frequently observed (Fig. 1) and leads to rupture. In fact, stress peaks in stress-strain curves correspond to the establishment of a shear band (Desrues 2005; Mokni and Desrues 1999). Therefore, the post peak or post localisation behaviour is important and needs to be properly modelled.

At large scale, the gallery excavation process induces in situ stress perturbations that engender the damage propagation. Diederichs (2003) indicates that damage accumulation leads to three distinct rock mass brittle failure mechanisms which can occur around underground galleries : macro-scale shear failure in case of high-stress environment, spalling in case of low-stress environment and unravelling which corresponds to tensile failure (Fig. 2). The author also mentions that dilating cracks appear close to the excavation wall because it is not restraint. Similar failure mechanisms are ob- 

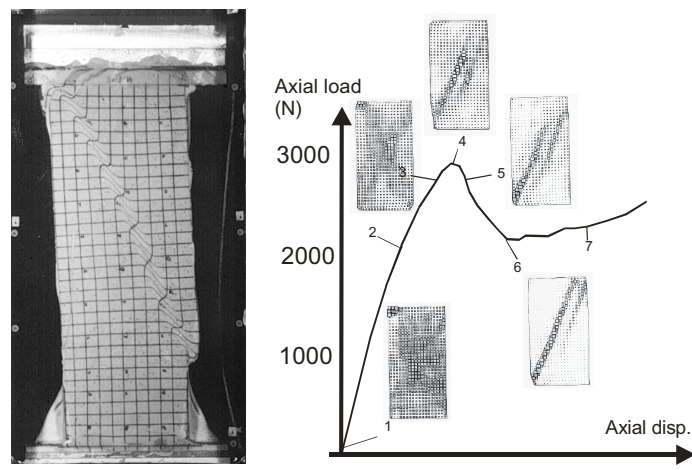

Fig. 1 Shear strain localisation and mechanical fracturing during a biaxial compression test on Hostun sand from Mokni and Desrues (1999)

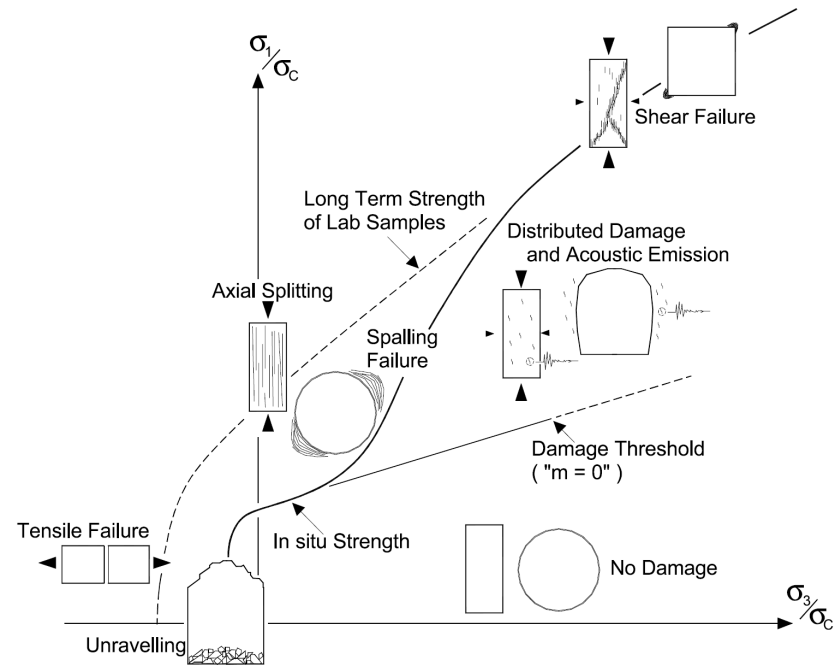

Fig. 2 Rock mass brittle failure mechanisms around gallery from Diederichs (2003)

served on small-scale laboratory tests. An excavation damaged zone composed of distributed damage and possible macroscale fracturing then develops close to the drift wall. Emsley et al (1997) and Tsang and Bernier (2004) define it as a zone dominated by geochemical and hydromechanical property changes that are mainly irreversible and which induce important modifications in flow and transport properties (Bossart et al 2002; Tsang et al 2005; Armand et al 2007), such as permeability increase (Fig. 3). These property modifications could alter the safety function of the rock, therefore the EDZ behaviour is a major issue concerning the long-term management of nuclear waste repository.

Focusing on the Callovo-Oxfordian claystone, in situ measurements and observations of fractures in the rock surrounding the Andra URL are conducted to characterise the EDZ. Let us consider the GED experimental gallery which is oriented in the direction of the minor horizontal principal stress. Armand et al (2014) and Cruchaudet et al (2010b) indicate that chevron fractures are noticeable around and at the front of this gallery as illustrated in Fig. 4. This fracturing struc-
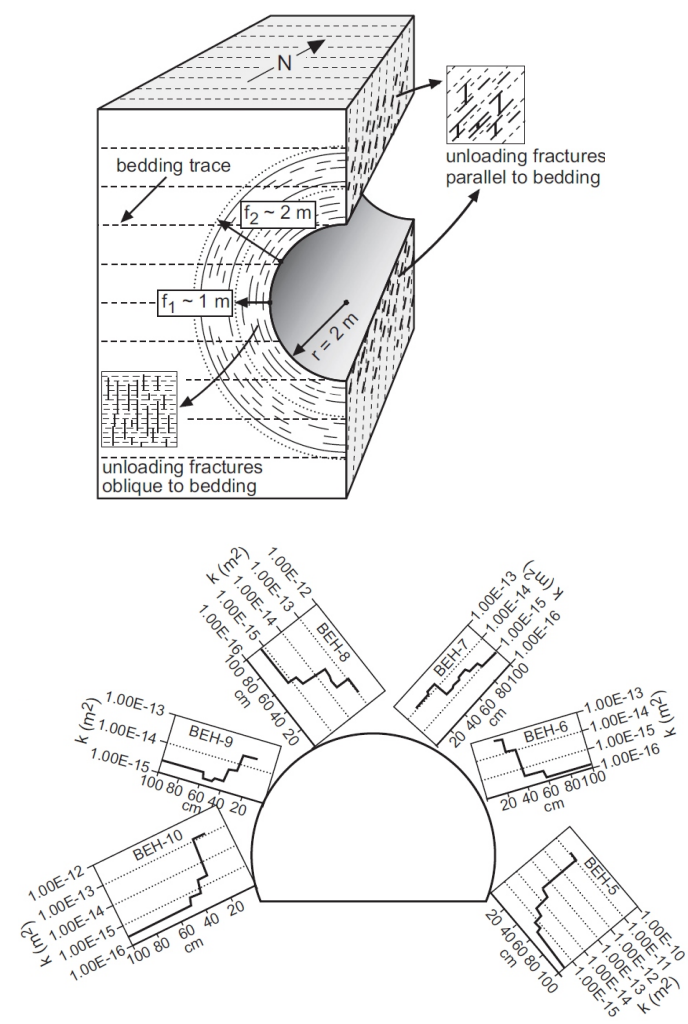

Fig. 3 Mechanical fracturing around a gallery in Opalinus clay (top) and permeability change (bottom) from Bossart et al (2002)

ture is similar to the one observed around Boom clay drill core by Blümling et al (2007). The extension of the fractured zone can be split in two sub-zones as shown in Fig. 5 : a zone with mixed fractures (shear and tensile) close to the gallery and a zone with only shear fractures further in the rock. Along the gallery, the extension of the total fractured zone is about 0.6 to 1.1 times the gallery diameter in the vertical direction and less than 0.1 diameter in the horizontal direction.

\subsection{Soil-atmosphere interaction}

When a material is in contact with the atmosphere, transfers between them take place. For porous materials like soils, gaseous (water vapour) transfers occur and may significantly modify the water saturation, especially close to the contact interface. These transfers occur in the case that water vapour reaches the contact interface. This is realised by fluid transfers (gas flows) inside the material that are mainly governed by capillary forces. These interface exchanges have to be carefully studied because, if they lead to the drainage and the desaturation of a material, they can create shrinkage or even dessication fracturing (Peron et al 2009a; Peron et al 2009b). 

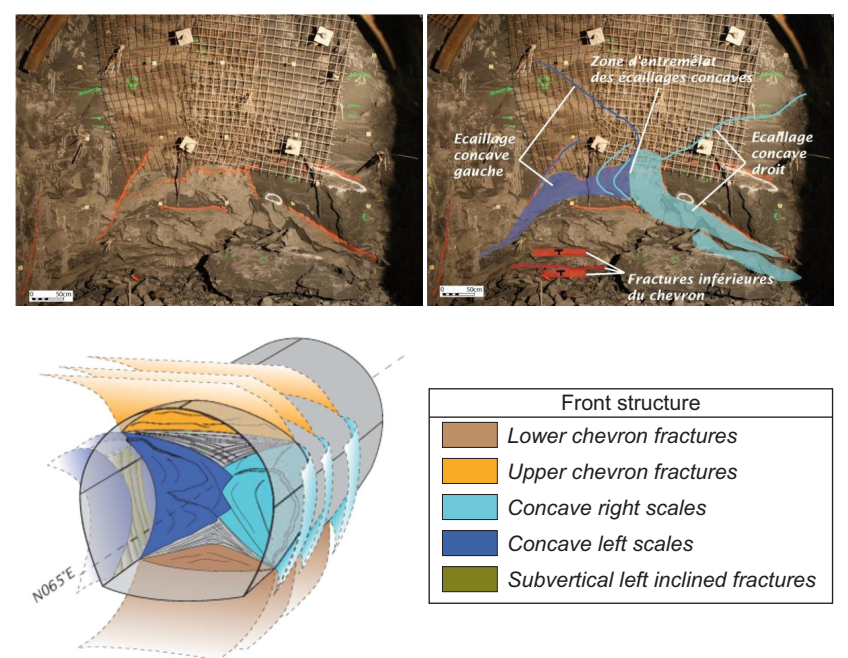

Fig. 4 Picture and schematic representation of the fractures at the front of a gallery of the Andra URL from Armand et al (2014) and Cruchaudet et al (2010b)
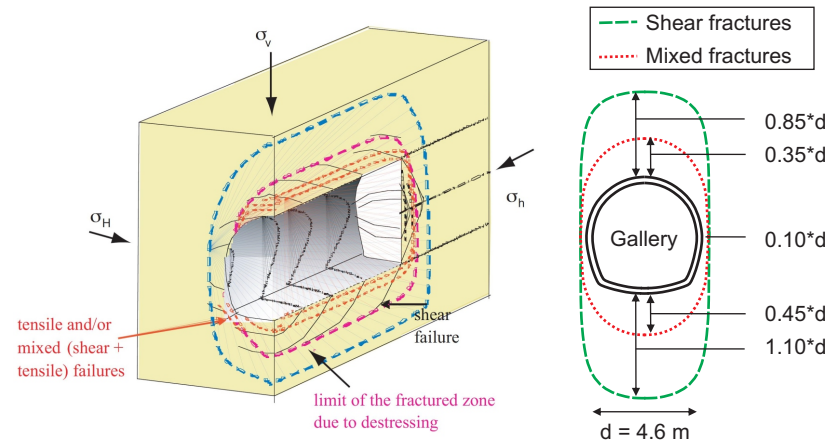

Fig. 5 Extension of shear and mixed fractures zones around a gallery of the Andra URL from Bordeau et al (2007) and Armand et al (2014)

Different laboratory tests are developed at small scale to study material evolution due to material-atmosphere interaction. In classical techniques, derived from chemical engineering methods, the suction in the material is controlled. One of them is to control the vapour phase by submitting samples to a relative humidity regulated with salt solutions in a desiccator (Delage et al 1998; Romero et al 2001; Young 1967). Another technique that reproduces air circulation is the convective drying test during which air is blew at the material surface (Ta 2009; Gerard et al 2010; Léonard et al 2005). Generally, the relative humidity, the temperature and the speed of the air are controlled during the drying. For example, Fig. 6 shows the result of a drying test that leads to the fracturing of a clay. In addition, an efficient tool to characterise the cracks development and evolution during a drying test performed on a small-scale sample is the Xray microtomography coupled to image analysis (Léonard et al 2002, 2003). It also allows the determination of internal moisture profiles and geometrical parameter changes that describe the shrinkage process.

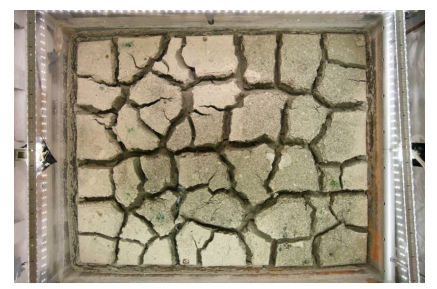

Fig. 6 Cracks network on the surface of the Romainville clay after drying from Ta (2009)

At repository scale, air ventilation is usually realised in the galleries composing underground structures during the excavation and maintenance phases. This could influence the short-term behaviour of underground repository structures. In fact, ventilation may drain the water from the rock which could influence the kinetics of desaturation as well as the stress field at drift wall if the drainage is important. Consequently, ventilation could affect the damaged zone (Matray et al 2007) by modifying its fracturing structure, size, and properties. To study the influence of rock-atmosphere interactions, ventilation tests are performed in URL. For instance, a ventilation test called SDZ is carried out by Andra (Cruchaudet et al 2010a) in France and the VE experiment is performed at the Mont Terri underground laboratory in Switzerland (Mayor et al 2007). The aim of these tests is to characterise the influence of a controlled ventilation in an experimental gallery on the hydro-mechanical behaviour of the rock mass and the damaged zone. The desaturation process, the permeability and the deformation of the surrounding clay rock are most particularly studied during the tests. These experiments indicate a parallelism between geological measurements of fractures and hydraulic measurements. In particular, open fractures that are connected to the gallery present modifications of the rock hydraulic characteristics and could therefore constitute a preferential flow path. The tensile fractures that develop close to the gallery wall induce an increase of permeability, which is not homogeneous in the damaged zone. Moreover, measurements of pore water pressure and water content in the rock close and far away from the gallery indicate that air ventilation induces a desaturation in a layer of few decimetres of thickness around the gallery (Charlier et al 2013).

These experimental studies on soil-atmosphere interaction, at small and large scale, emphasise the effect of shrinkage and dessication on cracking. They also give the general context and the potential applications of the present study. In the present study, the fractures are modelled and the effect of gallery ventilation and rock-atmosphere interaction on the cracks structure is taken into account in the hydromechanical model. However, the coupling with the permeability is not addressed. 


\section{Coupled local second gradient model in unsaturated conditions}

The fracturing evidences presented in the previous section highlight that damage around underground galleries develops as cracks and that strain localisation, mainly in shear band mode, appears prior to the fracture. Within the classical finite element framework, strain localisation depends on the mesh size and orientation (Collin et al 2009; Pietruszczak and Mróz 1981; Wu and Wang 2010; Zervos et al 2001b). An enhanced model, introducing an internal length scale, is therefore necessary to accurately model the post peak and localisation behaviour. Different regularisation approaches exist and can be distinguished into two main categories. In the first one, the constitutive law is enriched. The internal length scale is introduced in the constitutive model. As examples we can mention the gradient plasticity, which introduces gradient of internal variables (Aifantis 1984; de Borst and Mühlhaus 1992; Peerlings et al 1996a), and the nonlocal approaches (Bazant et al 1984; Pijaudier-Cabot and Bazant 1987; Peerlings et al 1996b), which are based on the use of non local internal variables. In the second category, kinematics are enriched. Within the scope of these methods, the continuum is enriched with microstructure effects : kinematics include the classical ones, the macrokinematics, and the microkinematics (Toupin 1962; Mindlin 1964; Germain 1973). Cosserat's model is one of the most famous (Cosserat and Cosserat 1909). Among the existing regularisation methods with kinematics enrichment, the local second gradient model (Chambon et al 1998; Chambon et al 2001) is chosen.

Geomaterials, like soils and claystone in this particular study, are porous media usually treated as the superposition of several continua (based on a mixture theory) as described by Coussy (2004). The different phases are the solid phase, composed of the grains assembly that forms the solid skeleton, and the pore fluids. The porous space between the solid grains is filled with two fluids : a wetting fluid corresponding to the liquid phase, generally water, and a nonwetting fluid corresponding to the gaseous phase, generally air. These phases are considered as immiscible and phase changes like evaporation are not taken into account. Unsaturated condition is considered, however a constant gas pressure is assumed.

\subsection{Balance equations}

The balance equations can be written for both phases or for the mixture and one of the phases. We chose the second way and we write the balance equations for the current porous material configuration, and for unit volume $\Omega^{t}$. The strain and rotation at microscale are described by a microkinematic gradient field, $v_{i j}$, within the context of microstructure continuum theory. Consequently, additional terms are added to the classical continuum mechanics through the internal virtual work principle. For a monophasic material with the current configuration $\Omega^{t}$ and for every kinematically admissible virtual displacement field $u_{i}^{*}$, the internal virtual work reads (Germain 1973) :

$W_{i n t}^{*}=\int_{\Omega^{t}}\left(\sigma_{i j}^{t} \frac{\partial u_{i}^{*}}{\partial x_{j}^{t}}+\tau_{i j}^{t}\left(v_{i j}^{*}-F_{i j}^{*}\right)+\Sigma_{i j k}^{t} h_{i j k}^{*}\right) d \Omega^{t}$

where $\sigma_{i j}$ is the Cauchy stress field, $v_{i j}^{*}$ is the virtual microkinematic gradient, $F_{i j}^{*}=\frac{\partial u_{i}^{*}}{\partial x_{j}^{t}}$ is the virtual macrodeformation gradient, $\tau_{i j}$ is an additional stress associated to the microstructure, also called the microstress, $h_{i j k}^{*}=\frac{\partial v_{i j}^{*}}{\partial x_{k}^{t}}$ is the virtual micro second gradient and $\Sigma_{i j k}$, which needs an additional constitutive law, is the double stress dual of the virtual micro second gradient. On the other hand, the external virtual work reads :

$W_{e x t}^{*}=\int_{\Gamma_{\sigma}^{t}}\left(\bar{t}_{i} u_{i}^{*}+\bar{T}_{i} D u_{i}^{*}\right) d \Gamma^{t}$

where $\bar{t}_{i}$ is the classical external traction force per unit area, $\bar{T}_{i}$ is an additional external double force per unit area, both applied on a part $\Gamma_{\sigma}^{t}$ of the boundary of $\Omega^{t} . D u_{i}^{*}$ is $u_{i}^{*}$ normal derivative and is given as $D u_{i}^{*}=\frac{\partial u_{i}^{*}}{\partial x_{k}^{t}} u_{\perp, k}^{t}$, where $u_{\perp, k}$ is $u_{i}^{*}$ normal vector.

The hypothesis of equality between the microkinematic and macrodeformation gradients is realised, $v_{i j}=F_{i j}=\frac{\partial u_{i}}{\partial x_{j}}$ leading to $v_{i j}^{*}=F_{i j}^{*}=\frac{\partial u_{i}^{*}}{\partial x_{j}}$, and is introduced through a field of Lagrange multipliers $\lambda_{i j}$ (Chambon et al 1998). The momentum balance equation is obtained from the equality between internal and external virtual works and reads in a weak form :

$$
\begin{aligned}
& \int_{\Omega^{t}}\left(\sigma_{i j}^{t} \frac{\partial u_{i}^{*}}{\partial x_{j}^{t}}+\Sigma_{i j k}^{t} \frac{\partial v_{i j}^{*}}{\partial x_{k}^{t}}-\lambda_{i j}^{t}\left(\frac{\partial u_{i}^{*}}{\partial x_{j}^{t}}-v_{i j}^{*}\right)\right) d \Omega^{t} \\
& =\int_{\Gamma_{\sigma}^{t}}\left(\bar{t}_{i} u_{i}^{*}+\bar{T}_{i} v_{i k}^{*} u_{\perp, k}^{t}\right) d \Gamma^{t}
\end{aligned}
$$

$\int_{\Omega^{t}} \lambda_{i j}^{*}\left(\frac{\partial u_{i}^{t}}{\partial x_{j}^{t}}-v_{i j}^{t}\right) d \Omega^{t}=0$

The second gradient theory was extended from monophasic to multiphasic medium by Collin et al (2006). The previous equations remain valid provided to define $\sigma_{i j}$ as Terzaghi's total stress and assuming that the double stress $\Sigma_{i j k}$ is independent of the pore water pressure. In addition to Eq. 3 and 4 and for every kinematically admissible virtual pore 
water pressure field $p_{w}^{*}$, the fluid mass balance equation is defined in a weak form :

$\int_{\Omega^{t}}\left(\dot{M}_{w}^{t} p_{w}^{*}-m_{w, i}^{t} \frac{\partial p_{w}^{*}}{\partial x_{i}^{t}}\right) d \Omega^{t}=\int_{\Omega^{t}} Q^{t} p_{w}^{*} d \Omega^{t}-\int_{\Gamma_{q}^{t}} \bar{q}^{t} p_{w}^{*} d \Gamma^{t}$

where $m_{w, i}$ is the water mass flow, $\dot{M}_{w}$ is the water mass variation, $Q^{t}$ is a water sink term and $\Gamma_{q}^{t}$ is the part of the boundary where the input water mass per unit area $\bar{q}^{t}$ is prescribed.

Collin et al (2006) describe the coupled problem under saturated conditions for a porous material fully saturated with water. In the present study, we extend the model to unsaturated conditions with a constant gas pressure and introduce the compressibility of the solid grain skeleton through Biot's coefficient. The total stress field is defined according to Bishop's postulate (Nuth and Laloui 2008), which corresponds to Biot's definition and takes into account partial saturation :

$\sigma_{i j}=\sigma_{i j}^{\prime}-b S_{r, w} p_{w} \delta_{i j}$

where $\sigma_{i j}^{\prime}$ is the Bishop's effective stress field, $b$ is Biot's coefficient, $S_{r, w}$ is the water degree of saturation, $p_{w}$ is the pore water pressure with $p_{w}<0$ if suction, $\delta_{i j}$ is the Kronecker symbol. In Eq. 6, the stress field is defined under material mechanics convention in which compressive stress is negative.

\subsection{Solid and fluid phases behaviour}

We develop further Eq. 5 by including the solid and fluid phases behaviour. For the fluid phase, a flow model is required to reproduce water transfer in partially saturated porous media. The fluid mass flow reads :

$m_{w, i}=\rho_{w} q_{w, i}$

where $\rho_{w}$ is the water density and $q_{w, i}$ is the average speed of the liquid phase relative to the solid phase. The advection of the liquid phase is modelled by Darcy's flow :

$q_{w, i}=-\frac{k_{i j} k_{r, w}}{\mu_{w}} \frac{\partial p_{w}}{\partial x_{j}}$

where $k_{i j}$ is the intrinsic hydraulic permeability tensor, $k_{r, w}$ is the relative water permeability, which depends on the water degree of saturation, and $\mu_{w}$ is the water dynamic viscosity. The fluid mass inside a porous material volume $\Omega$ corresponds to :

$M_{w}=\rho_{w} n S_{r, w} \Omega$ where $n$ is the material porosity. The time variation of the fluid mass reads :

$\dot{M}_{w}=\dot{\rho}_{w} n S_{r, w} \Omega+\rho_{w} \dot{n} S_{r, w} \Omega+\rho_{w} n \dot{S}_{r, w} \Omega+\rho_{w} n S_{r, w} \dot{\Omega}$

The isotropic compressibility of the fluid follows the relation :

$\frac{\dot{\rho}_{w}}{\rho_{w}}=\frac{\dot{p}_{w}}{\chi_{w}}$

where $1 / \chi_{w}$ is the water compressibility.

Considering now the solid phase behaviour (Detournay and Cheng 1993; Coussy 2004), the solid density variation is linked to the variation of pore water pressure and mean effective stress :

$\frac{\dot{\rho}_{s}}{\rho_{s}}=\frac{(b-n) S_{r, w} \dot{p}_{w}-\dot{\sigma}^{\prime}}{(1-n) K_{s}}$

where $\rho_{s}$ is the solid grain density, $K_{s}$ is the isotropic bulk modulus of the solid grains and $\sigma^{\prime}$ is Bishop's mean effective stress. The isotropic bulk modulus of the solid grains is calculated from the drained bulk modulus of the poroelastic material $K$ and Biot's coefficient, which represents the compressibility of the solid grain skeleton :

$b=1-\frac{K}{K_{s}}$

$K=\frac{E}{3(1-2 v)}$

where $E$ and $v$ are the drained Young's modulus and the drained Poisson's ratio respectively. The porosity time variation is defined by (Coussy 2004) :

$\dot{n}=(b-n)\left(\frac{S_{r, w} \dot{p}_{w}}{K_{s}}+\dot{\varepsilon}_{v}\right)$

where $\dot{\varepsilon}_{v}$ is the time variation of the volumetric strain $\varepsilon_{v}=$ $\varepsilon_{i j} \delta_{i j}=\varepsilon_{i i}, \varepsilon_{i j}$ being the total strain tensor.

Finally, the time variation of the fluid mass detailed in Eq. 10 becomes, by including the fluid mass behaviour of Eq. 11, the porosity variation of Eq. 15 and considering an unit volume $\Omega$ :

$\dot{M}_{w}=\rho_{w}\left(\frac{\dot{p}_{w}}{\chi_{w}} n S_{r, w}+\frac{\dot{p}_{w}}{K_{s}}(b-n) S_{r, w}^{2}+b \dot{\varepsilon}_{v} S_{r, w}+n \dot{S}_{r, w}\right)$ 
3.3 Iterative procedures for the coupled finite element formulation

Since the previous balance equations are not numerically verified for any instant $t$, it is necessary to discretise in time steps $\Delta t$ which leads to two configurations. One configuration, $\Omega^{t}$, is in equilibrium with the boundary conditions at a given time $t$ and the other, $\Omega^{\tau}$, is not at equilibrium at a time $\tau=t+\Delta t$. The aim is to determine the new configuration at the end of the time step. This solution, which is not at equilibrium, is guessed and denoted as $\Omega^{\tau 1}$. Both configurations at time $t$ and $\tau 1$ are assumed to be known and residuals, i.e. non-equilibrium forces, $\Delta_{R}^{\tau 1}, \Delta_{S}^{\tau 1}$ and $\Delta_{W}^{\tau 1}$ are defined. The objective then is to find another configuration $\Omega^{\tau 2}$, close to $\Omega^{\tau 1}$, for which the non-equilibrium forces vanish. Substracting the balance equations of the two configurations, rewriting the equations for $\Omega^{\tau 2}$ in $\Omega^{\tau 1}$ configuration, assuming that $\bar{t}_{i}, \bar{q}$ and $Q$ are position independent and assuming that $\bar{T}_{i}$ vanishes, gives :

$$
\begin{aligned}
& \int_{\Omega^{\tau 1}} \frac{\partial u_{i}^{*}}{\partial x_{l}^{\tau 1}}\left(\sigma_{i j}^{\tau 2} \frac{\partial x_{l}^{\tau 1}}{\partial x_{j}^{\tau 2}} \operatorname{det} F-\sigma_{i l}^{\tau 1}\right) \\
& +\frac{\partial v_{i j}^{*}}{\partial x_{l}^{\tau 1}}\left(\Sigma_{i j k}^{\tau 2} \frac{\partial x_{l}^{\tau 1}}{\partial x_{k}^{\tau 2}} \operatorname{det} F-\Sigma_{i j l}^{\tau 1}\right) \\
& -\frac{\partial u_{i}^{*}}{\partial x_{l}^{\tau 1}}\left(\lambda_{i j}^{\tau 2} \frac{\partial x_{l}^{\tau 1}}{\partial x_{j}^{\tau 2}} \operatorname{det} F-\lambda_{i l}^{\tau 1}\right) \\
& +v_{i j}^{*}\left(\lambda_{i j}^{\tau 2} \operatorname{det} F-\lambda_{i j}^{\tau 1}\right) d \Omega^{\tau 1}=-\Delta_{R}^{\tau 1} \\
& \int_{\Omega^{\tau 1}} \lambda_{i j}^{*}\left(\frac{\partial u_{i}^{\tau 2}}{\partial x_{k}^{\tau 1}} \frac{\partial x_{k}^{\tau 1}}{\partial x_{j}^{\tau 2}} \operatorname{det} F-\frac{\partial u_{i}^{\tau 1}}{\partial x_{j}^{\tau 1}}\right) \\
& -\lambda_{i j}^{*}\left(v_{i j}^{\tau 2} \operatorname{det} F-v_{i j}^{\tau 1}\right) d \Omega^{\tau 1}=-\Delta_{S}^{\tau 1} \\
& \int_{\Omega^{\tau 1}} p_{w}^{*}\left(\dot{M}_{w}^{\tau 2} \operatorname{det} F-\dot{M}_{w}^{\tau 1}\right)
\end{aligned}
$$

$$
-\frac{\partial p_{w}^{*}}{\partial x_{l}^{\tau 1}}\left(m_{w, i}^{\tau 2} \frac{\partial x_{l}^{\tau 1}}{\partial x_{i}^{\tau 2}} \operatorname{det} F-m_{w, l}^{\tau 1}\right) d \Omega^{\tau 1}=-\Delta_{W}^{\tau 1}
$$

where $\operatorname{det} F$ is the Jacobian of $F_{i j}$ :

$\operatorname{det} F=\frac{\partial x_{i}^{\tau 2}}{\partial x_{j}^{\tau 1}}=1+\frac{\partial d u_{i}^{t}}{\partial x_{i}^{t}}$

By making the two configurations tend towards each other, the variations between them can be defined as follow :

$d u_{i}^{t}=x_{i}^{\tau 2}-x_{i}^{\tau 1}$

$d v_{i j}^{t}=v_{i j}^{\tau 2}-v_{i j}^{\tau 1}$

$d \lambda_{i j}^{t}=\lambda_{i j}^{\tau 2}-\lambda_{i j}^{\tau 1}$

$$
\begin{aligned}
& d \sigma_{i j}^{t}=\sigma_{i j}^{\tau 2}-\sigma_{i j}^{\tau 1}=d \sigma_{i j}^{t}-b S_{r, w}^{t} d p_{w}^{t} \delta_{i j} \\
& d \Sigma_{i j k}^{t}=\Sigma_{i j k}^{\tau 2}-\Sigma_{i j k}^{\tau 1} \\
& d n^{t}=n^{\tau 2}-n^{\tau 1}=\left(b-n^{t}\right)\left(\frac{S_{r, w}^{t} d p_{w}^{t}}{K_{s}}+d \varepsilon_{v}^{t}\right) \\
& d \rho_{w}^{t}=\rho_{w}^{\tau 2}-\rho_{w}^{\tau 1}=\rho_{w}^{t} \frac{d p_{w}^{t}}{\chi_{w}} \\
& d \rho_{s}^{t}=\rho_{s}^{\tau 2}-\rho_{s}^{\tau 1}=\rho_{s}^{t} \frac{\left(b-n^{t}\right) S_{r, w}^{t} d p_{w}^{t}-d \sigma^{t}}{\left(1-n^{t}\right) K_{s}} \\
& d \varepsilon_{v}^{t}=\frac{d \Omega^{t}}{\Omega^{t}}=\frac{\partial d u_{i}^{t}}{\partial x_{i}^{t}}
\end{aligned}
$$

The balance equations can be rewritten by taking into account the above variations. A convenient formulation of the coupled finite element problem is to write the equations in matricial form in order to define the stiffness (tangent) matrix :

$\int_{\Omega^{t}}\left[U_{(x, y)}^{*, t}\right]^{T}\left[E^{t}\right]\left[d U_{(x, y)}^{t}\right] d \Omega^{t}=-\Delta_{R}^{t}-\Delta_{S}^{t}-\Delta_{W}^{t}$

The matrices $\left[U_{(x, y)}^{*, t}\right],\left[d U_{(x, y)}^{t}\right]$ and $\left[E^{t}\right]$ are detailed in Collin et al (2006). The stiffness matrix is defined as follow :

$$
\left[E^{t}\right]_{25 \times 25}=\left[\begin{array}{cccccc}
E_{1_{4 \times 4}}^{t} & 0_{4 \times 2} & K_{W M_{4 \times 3}}^{t} & 0_{4 \times 8} & 0_{4 \times 4} & -I_{4 \times 4} \\
G_{1_{2 \times 4}}^{t} & 0_{2 \times 2} & G_{2 \times 3}^{t} & 0_{2 \times 8} & 0_{2 \times 4} & 0_{2 \times 4} \\
K_{M W_{3 \times 4}}^{t} & 0_{3 \times 2} & K_{W W_{3 \times 3}}^{t} & 0_{3 \times 8} & 0_{3 \times 4} & 0_{3 \times 4} \\
E_{28 \times 4}^{t} & 0_{8 \times 2} & 0_{8 \times 3} & D_{8 \times 8}^{t} & 0_{8 \times 4} & 0_{8 \times 4} \\
E_{3_{4 \times 4}}^{t} & 0_{4 \times 2} & 0_{4 \times 3} & 0_{4 \times 8} & 0_{4 \times 4} & I_{4 \times 4} \\
E_{44 \times 4}^{t} & 0_{4 \times 2} & 0_{4 \times 3} & 0_{4 \times 8} & -I_{4 \times 4} & 0_{4 \times 4}
\end{array}\right]
$$

where $\left[G_{1}^{t}\right]_{2 \times 4}$ and $\left[G_{2}^{t}\right]_{2 \times 3}$ are null matrices because no contribution of the gravity volume force is considered, and the matrices $\left[E_{1}^{t}\right]_{4 \times 4},\left[E_{2}^{t}\right]_{8 \times 4},\left[E_{3}^{t}\right]_{4 \times 4},\left[E_{4}^{t}\right]_{4 \times 4}$ and $\left[D^{t}\right]_{8 \times 8}$ are the same as the ones used in the local second gradient model for monophasic medium (Chambon and Moullet 2004). The other matrices are detailed below. The stiffness matrix of the flow problem is :

$$
\left[K_{W W}^{t}\right]_{3 \times 3}=\left[\begin{array}{ccc}
\rho_{w}^{t} \frac{k_{11} k_{r, w}^{t}}{\mu_{w}} & \rho_{w}^{t} \frac{k_{12} k_{r, w}^{t}}{\mu_{w}} & K_{W W_{1,3}}^{t} \\
\rho_{w}^{t} \frac{k_{21} k_{r, w}^{t}}{\mu_{w}} & \rho_{w}^{t} \frac{k_{22} k_{r, w}^{t}}{\mu_{w}} & K_{W W_{2,3}}^{t} \\
0 & 0 & K_{W W_{3,3}}^{t}
\end{array}\right]
$$

where

$$
\begin{aligned}
& K_{W W_{1,3}}^{t}=\frac{\rho_{w}^{t}}{\mu_{w}}\left(\frac{k_{r, w}^{t}}{\chi_{w}}+\frac{\partial k_{r, w}^{t}}{\partial p_{w}^{t}}\right)\left(k_{11} \frac{\partial p_{w}^{t}}{\partial x_{1}^{t}}+k_{12} \frac{\partial p_{w}^{t}}{\partial x_{2}^{t}}\right) \\
& K_{W W_{2,3}}^{t}=\frac{\rho_{w}^{t}}{\mu_{w}}\left(\frac{k_{r, w}^{t}}{\chi_{w}}+\frac{\partial k_{r, w}^{t}}{\partial p_{w}^{t}}\right)\left(k_{21} \frac{\partial p_{w}^{t}}{\partial x_{1}^{t}}+k_{22} \frac{\partial p_{w}^{t}}{\partial x_{2}^{t}}\right)
\end{aligned}
$$




$$
\begin{aligned}
K_{W W_{3,3}}^{t}= & \frac{\rho_{w}^{t}}{\chi_{w}} \frac{\dot{p}_{w}^{t}}{\chi_{w}} n^{t} S_{r, w}^{t}+\frac{\rho_{w}^{t}}{\chi_{w} d t} n^{t} S_{r, w}^{t} \\
& +2 \frac{\rho_{w}^{t}}{K_{s}} \frac{\dot{p}_{w}^{t}}{\chi_{w}}\left(b-n^{t}\right)\left(S_{r, w}^{t}\right)^{2}+\rho_{w}^{t} \frac{\dot{p}_{w}^{t}}{\chi_{w}} n^{t} \frac{\partial S_{r, w}^{t}}{\partial p_{w}^{t}} \\
& -\frac{\rho_{w}^{t}}{K_{s}} \frac{\dot{p}_{w}^{t}}{K_{s}}\left(b-n^{t}\right)\left(S_{r, w}^{t}\right)^{3} \\
& +2 \rho_{w}^{t}\left(b-n^{t}\right) \frac{\dot{p}_{w}^{t}}{K_{s}} S_{r, w}^{t} \frac{\partial S_{r, w}^{t}}{\partial p_{w}^{t}} \\
& +\frac{\rho_{w}^{t}}{K_{s} d t}\left(b-n^{t}\right)\left(S_{r, w}^{t}\right)^{2}+\frac{\rho_{w}^{t}}{\chi_{w}} b \dot{\varepsilon}_{v}^{t} S_{r, w}^{t} \\
& +\rho_{w}^{t} b \dot{\varepsilon}_{v}^{t} \frac{\partial S_{r, w}^{t}}{\partial p_{w}^{t}}+\frac{\rho_{w}^{t}}{\chi_{w}} n^{t} \dot{S}_{r, w}^{t} \\
& +\frac{\rho_{w}^{t}}{K_{s}}\left(b-n^{t}\right) S_{r, w}^{t} \dot{S}_{r, w}^{t}+\frac{\rho_{w}^{t}}{d t} n^{t} \frac{\partial S_{r, w}^{t}}{\partial p_{w}^{t}}
\end{aligned}
$$
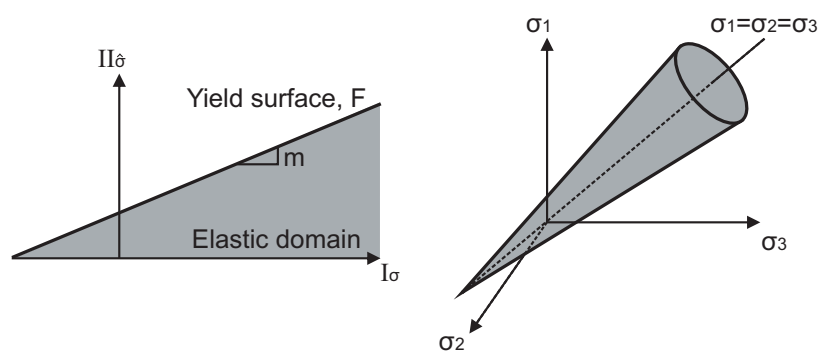

Fig. 7 Drucker-Prager yield surface in the stress invariants plane (left) and in the principal stress space (right)

\subsection{First gradient mechanical law}

The constitutive mechanical law used for the clayey rock is a non-associated elastoplastic internal friction model with linear elasticity and a Drucker-Prager yield surface (Fig. 7). Moreover, this mechanical model is affected by suction. Under soil mechanics convention, in which compressive stress is positive, the yield surface equation reads :

$F \equiv I I_{\hat{\sigma}}-m\left(I_{\sigma}+\frac{3 c}{\tan \phi_{c}}\right)=0$

where $I_{\sigma}$ is the first stress invariant, $I I_{\hat{\sigma}}$ is the second deviatoric stress invariant, $\phi_{c}$ is the compression friction angle, $c$ is the cohesion and $m$ is a parameter of the yield surface. The first and second stress invariants are given by :

$I_{\sigma}=\sigma_{i j} \delta_{i j}=\sigma_{i i}$

$I_{\hat{\sigma}}=\sqrt{\frac{1}{2} \hat{\sigma}_{i j} \hat{\sigma}_{i j}}$

where $\hat{\sigma}_{i j}$ is the deviatoric stress tensor:

$\hat{\sigma}_{i j}=\sigma_{i j}-\frac{I_{\sigma}}{3} \delta_{i j}$

The parameter $m$ is defined as follow :

$$
\begin{aligned}
C^{t}= & \rho_{w}^{t} \frac{\dot{p}_{w}^{t}}{\chi_{w}}\left(b-n^{t}\right) S_{r, w}^{t}-\rho_{w}^{t} \frac{\dot{p}_{w}^{t}}{K_{s}}\left(b-n^{t}\right)\left(S_{r, w}^{t}\right)^{2} \\
& +\rho_{w}^{t}\left(\frac{b}{d t}-\frac{\dot{\Omega}^{t}}{\Omega^{t}}\right) S_{r, w}^{t}+\rho_{w}^{t}\left(b-n^{t}\right) \dot{S}_{r, w}^{t}
\end{aligned}
$$

\section{Constitutive models}

Constitutive models and their parameters are required to study the numerical application of a gallery drilling in the CallovoOxfordian claystone. These models are : firstly, a model for the classical mechanical part, also called the first gradient mechanical law, then a model for the enriched part, called the second gradient mechanical law, and finally, a flow model. The latter is completed by the definition of the retention and water relative permeability curves.

$$
m=\frac{2 \sin \phi_{c}}{\sqrt{3}\left(3-\sin \phi_{c}\right)}
$$

Laboratory experiments put in evidence that water content and desaturation influence the behaviour of clayey rock. The material suction has an influence on the elastic and plastic properties of claystone, it induces an increase of resistance. Experimental results from Zhang et al (2013) indicate an evolution of Young's modulus and uniaxial compression strength, $R_{c}$, with the relative humidity, $R H$. The latter is linked to the suction through Kelvin's law (Eq. 59) and the uniaxial compression strength is linked to the material cohesion through the following relation :

$R_{c}=\frac{2 \cos \phi_{c}}{1-\sin \phi_{c}} c$ 


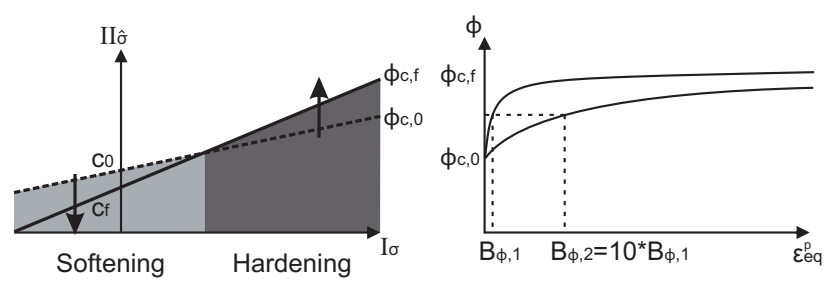

Fig. 8 Hardening/softening of the Drucker-Prager model : yield surface (left), hyperbolic relation for two values of coefficient $B_{\phi}$ (right)

Following the work of Zhang et al (2013) and assuming no evolution of the friction angle with the suction, linear evolutions of Young's modulus and cohesion with capillary pressure $p_{c}$ are introduced in the model, for $p_{c}>0$ :

$\frac{E}{E_{\text {sat }}}=1+\beta_{E} p_{c}$

$\frac{c}{c_{\text {sat }}}=\frac{R_{c}}{R_{c, s a t}}=1+\beta_{c} p_{c}$

where $E_{\text {sat }}$ is the saturated Young's modulus, $c_{\text {sat }}$ is the saturated cohesion, $R_{c, s a t}$ is the saturated uniaxial compression strength, $p_{c}$ is the capillary pressure corresponding to the matric suction $p_{c}=p_{g}-p_{w}$ and $p_{g}$ is the gas pressure. Furthermore, $\beta_{E}$ and $\beta_{c}$ are two parameters determined from experimental data and by the classic least squares fitting procedure (Table 1).

The model allows considering friction angle and cohesion isotropic hardening and/or softening as a function of Von Mises' equivalent plastic strain $\varepsilon_{e q}^{p}$ (Fig. 8). This equivalent plastic strain is defined as follow :

$\varepsilon_{e q}^{p}=\sqrt{\frac{2}{3} \hat{\varepsilon}_{i j}^{p} \hat{\varepsilon}_{i j}^{p}}$

where $\hat{\varepsilon}_{i j}^{p}$ is the deviatoric plastic strain tensor calculated from the plastic strain tensor $\varepsilon_{i j}^{p}$ :

$\hat{\varepsilon}_{i j}^{p}=\varepsilon_{i j}^{p}-\frac{\varepsilon_{i i}^{p}}{3} \delta_{i j}$

Hyperbolic functions are used for the hardening/softening (Barnichon 1998) :

$\phi_{c}=\phi_{c, 0}+\frac{\left(\phi_{c, f}-\phi_{c, 0}\right) \varepsilon_{e q}^{p}}{B_{\phi}+\varepsilon_{e q}^{p}}$

$c_{s a t}=c_{0}+\frac{\left(c_{f}-c_{0}\right) \varepsilon_{e q}^{p}}{B_{c}+\varepsilon_{e q}^{p}}$

where $\phi_{c, 0}$ and $\phi_{c, f}$ are the initial and final compression friction angles, $c_{0}$ and $c_{f}$ are the initial and final saturated cohesions, and the coefficients $B_{\phi}$ and $B_{c}$ are the values of the equivalent plastic strain for which half of the hardening/softening on friction angle and cohesion is achieved.

\subsection{Second gradient mechanical law}

The second gradient law gives the double stress as a function of the micro second gradient. It is a linear elastic law with isotropic linear relationship deduced from Mindlin (1965) :

$$
\left[\begin{array}{l}
\tilde{\Sigma}_{111} \\
\tilde{\Sigma}_{112} \\
\tilde{\Sigma}_{121} \\
\tilde{\Sigma}_{122} \\
\tilde{\Sigma}_{211} \\
\tilde{\Sigma}_{212} \\
\tilde{\Sigma}_{221} \\
\tilde{\Sigma}_{222}
\end{array}\right]=D\left[\begin{array}{cccccccc}
1 & 0 & 0 & 0 & 0 & \frac{1}{2} & \frac{1}{2} & 0 \\
0 & \frac{1}{2} & \frac{1}{2} & 0 & -\frac{1}{2} & 0 & 0 & \frac{1}{2} \\
0 & \frac{1}{2} & \frac{1}{2} & 0 & -\frac{1}{2} & 0 & 0 & \frac{1}{2} \\
0 & 0 & 0 & 1 & 0 & -\frac{1}{2} & -\frac{1}{2} & 0 \\
0 & -\frac{1}{2} & -\frac{1}{2} & 0 & 1 & 0 & 0 & 0 \\
\frac{1}{2} & 0 & 0 & -\frac{1}{2} & 0 & \frac{1}{2} & \frac{1}{2} & 0 \\
\frac{1}{2} & 0 & 0 & -\frac{1}{2} & 0 & \frac{1}{2} & \frac{1}{2} & 0 \\
0 & \frac{1}{2} & \frac{1}{2} & 0 & 0 & 0 & 0 & 0
\end{array}\right]\left[\begin{array}{l}
\frac{\partial \dot{v}_{11}}{\partial x_{1}} \\
\frac{\partial \dot{v}_{11}}{\partial x_{2}} \\
\frac{\partial \dot{v}_{12}}{\partial x_{1}} \\
\frac{\partial \dot{v}_{12}}{\partial x_{2}} \\
\frac{\partial \dot{v}_{21}}{\partial x_{1}} \\
\frac{\partial \dot{v}_{21}}{\partial x_{2}} \\
\frac{\partial \dot{v}_{22}}{\partial x_{1}} \\
\frac{\partial \dot{v}_{22}}{\partial x_{2}}
\end{array}\right]
$$

It depends on one constitutive elastic parameter $D$ that represents the physical microstructure. The internal length scale relevant for the shear band width is related to this parameter (Chambon et al 1998; Kotronis et al 2007). In Eq. 52, $\dot{v}_{i j}$ is the time derivative of $v_{i j}$ and $\tilde{\Sigma}_{i j k}$ is the Jaumann double stress rate (Collin et al 2006) :

$\tilde{\Sigma}_{i j k}=\dot{\Sigma}_{i j k}+\Sigma_{l j k} \omega_{l i}+\Sigma_{i m k} \omega_{m j}+\Sigma_{i j p} \omega_{p k}$

where $\dot{\Sigma}_{i j k}$ is the time derivative of $\Sigma_{i j k}$, which is independent of the pore water pressure, and $\omega_{i j}$ is the spin tensor.

\subsection{Retention and water relative permeability curves}

The retention curve is given by van Genuchten's model from van Genuchten (1980) :

$S_{r, w}=S_{r e s}+\frac{S_{\max }-S_{r e s}}{\left(1+\left(\frac{p_{c}}{P_{r}}\right)^{N}\right)^{M}}$

where $S_{\text {res }}$ and $S_{\max }$ are the residual and maximum water degree of saturation respectively, $N$ and $M=1-\frac{1}{N}$ are the coefficients of van Genuchten's model and $P_{r}$ is the air entry pressure. The water relative permeability curve is given by Mualem - van Genuchten's model (van Genuchten 1980) :

$k_{r, w}=\sqrt{S_{r, w}}\left(1-\left(1-S_{r, w}^{1 / M}\right)^{M}\right)^{2}$

\subsection{Mechanical and hydraulic parameters}

The hydro-mechanical parameters of the Callovo-Oxfordian claystone needed for the models come mainly from Charlier et al (2013). In this article, the authors present a synthesis of the main parameters obtained from laboratory testing and from the literature. The parameters of van Genuchten's model also come from experimental data fitting (Fig. 9). All the parameters values are detailed in Tables 1 and 2 . 
Table 1 Mechanical parameters of the Callovo-Oxfordian claystone

\begin{tabular}{|c|c|c|c|}
\hline Symbol & Name & Value & Unit \\
\hline$E_{\text {sat }}$ & Saturated Young's modulus & 4000 & $M P a$ \\
\hline$\beta_{E}$ & $\begin{array}{l}\text { Young's modulus parameter } \\
\text { for suction influence }\end{array}$ & $5.74 \times 10^{-9}$ & $P a^{-1}$ \\
\hline$v$ & Drained poisson's ratio & 0.3 & - \\
\hline$b$ & Biot's coefficient & 0.6 & - \\
\hline$\rho$ & Density & 2300 & $\mathrm{~kg} / \mathrm{m}^{3}$ \\
\hline$\psi$ & Dilatancy angle & 0.5 & $\circ$ \\
\hline$\phi_{c, 0}$ & $\begin{array}{l}\text { Initial compression friction } \\
\text { angle }\end{array}$ & 10 & $\circ$ \\
\hline$\phi_{c, f}$ & $\begin{array}{l}\text { Final compression friction } \\
\text { angle }\end{array}$ & 20 & $\circ$ \\
\hline$B_{\phi}$ & $\begin{array}{l}\text { Friction angle hardening } \\
\text { coefficient }\end{array}$ & 0.002 & - \\
\hline$c_{0}$ & Initial saturated cohesion & 3 & $M P a$ \\
\hline$c_{f}$ & Final saturated cohesion & 0.3 & $M P a$ \\
\hline$B_{c}$ & $\begin{array}{l}\text { Cohesion softening } \\
\text { coefficient }\end{array}$ & 0.003 & - \\
\hline$\beta_{c}$ & $\begin{array}{l}\text { Cohesion parameter for } \\
\text { suction influence }\end{array}$ & $11.86 \times 10^{-9}$ & $P a^{-1}$ \\
\hline$D$ & $\begin{array}{l}\text { Second gradient elastic } \\
\text { modulus }\end{array}$ & 5000 & $N$ \\
\hline
\end{tabular}

Table 2 Hydraulic parameters of the Callovo-Oxfordian claystone

\begin{tabular}{|c|c|c|c|}
\hline Symbol & Name & Value & Unit \\
\hline$k_{x x}$ & $\begin{array}{l}\text { Horizontal intrinsic water } \\
\text { permeability }\end{array}$ & $4 \times 10^{-20}$ & $m^{2}$ \\
\hline$k_{y y}$ & $\begin{array}{l}\text { Vertical intrinsic water } \\
\text { permeability }\end{array}$ & $1.33 \times 10^{-20}$ & $m^{2}$ \\
\hline$n$ & Porosity & 0.18 & - \\
\hline$M$ & van Genuchten coefficient & 0.33 & - \\
\hline$N$ & van Genuchten coefficient & 1.49 & - \\
\hline$P_{r}$ & $\begin{array}{l}\text { van Genuchten air entry } \\
\text { pressure }\end{array}$ & 15 & $\mathrm{MPa}$ \\
\hline$S_{\max }$ & $\begin{array}{l}\text { Maximum water degree of } \\
\text { saturation }\end{array}$ & 1 & - \\
\hline$S_{\text {res }}$ & $\begin{array}{l}\text { Residual water degree of } \\
\text { saturation }\end{array}$ & 0.01 & - \\
\hline$\mu_{w}$ & Water dynamic viscosity & 0.001 & Pas \\
\hline $1 / \chi_{w}$ & Water compressibility & 0 & $P a^{-1}$ \\
\hline
\end{tabular}
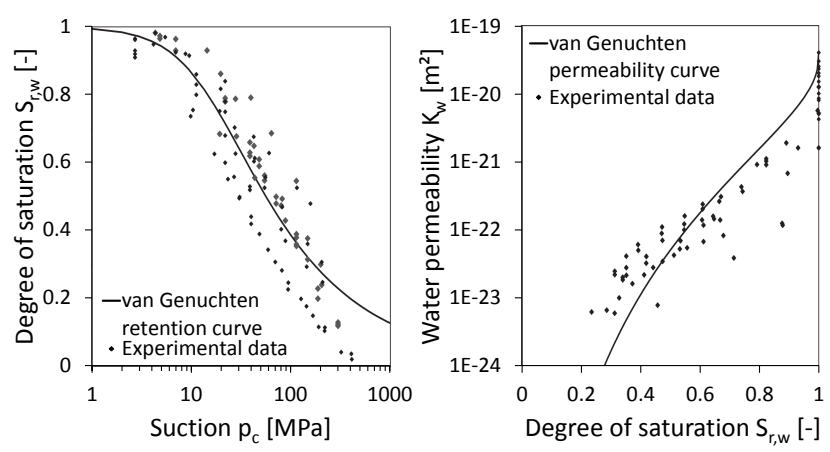

Fig. 9 Retention curve (left) and horizontal water permeability curve (right) of the Callovo-Oxfordian claystone, based on experimental data fitting of van Genuchten's model from Charlier et al (2013)
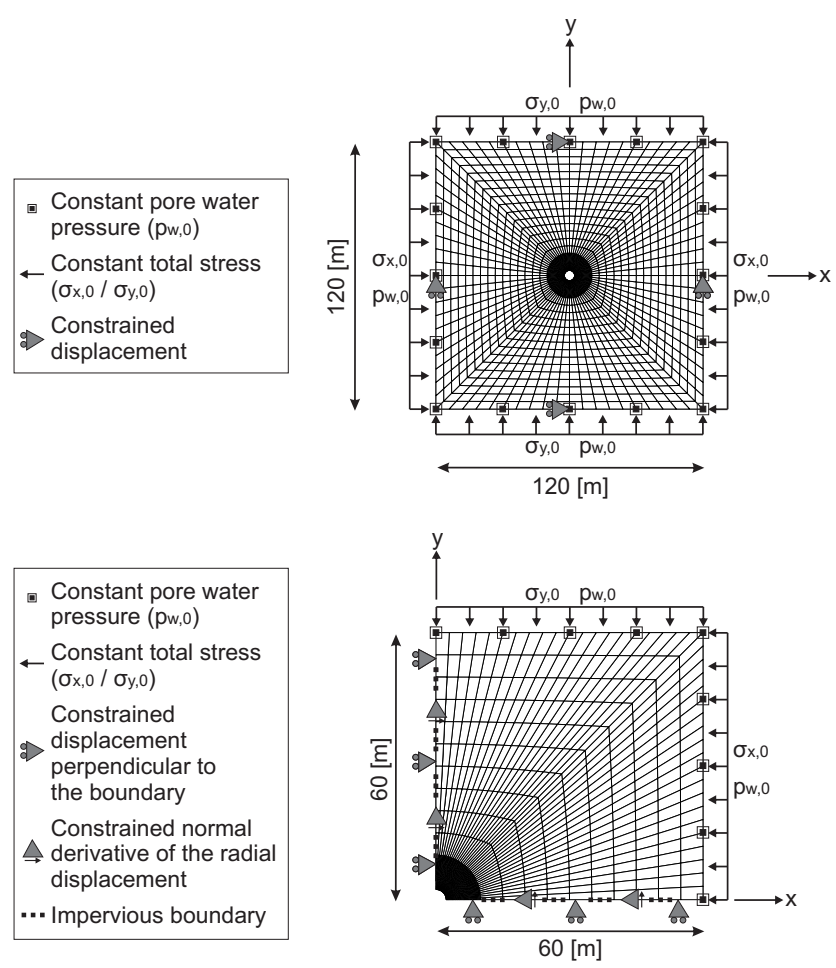

Fig. 10 Schematic representation of the model used for the modelling of a gallery excavation : full gallery (top), quarter of a gallery (bottom)

\section{Numerical simulations}

A hydro-mechanical modelling of a gallery excavation is performed in two-dimensional plane strain state. It takes into account the hydraulic permeability anisotropy (Table 2) and the initial anisotropic stress state corresponding to a gallery of the Andra URL drilled in Callovo-Oxfordian claystone (Wileveau et al 2007) :

$$
\begin{gathered}
p_{w, 0}=4.5[\mathrm{MPa}] \\
\sigma_{y, 0}=\sigma_{z, 0}=12[\mathrm{MPa}] \\
\sigma_{x, 0}=1.3 \sigma_{y, 0}=15.6[\mathrm{MPa}]
\end{gathered}
$$

where $p_{w, 0}$ is the initial pore water pressure, $\sigma_{y, 0}$ is the vertical principal total stress, $\sigma_{z, 0}$ is the minor horizontal principal total stress and $\sigma_{x, 0}$ is the major horizontal principal total stress. The modelled gallery has a radius of 2.3 meters, is oriented in the direction of the minor horizontal principal stress and gravity is not taken into account in this model.

A schematic representation of the models, the meshes and the boundary conditions is detailed in Fig. 10. Two meshes are used : a full gallery and a quarter of a gallery. The mesh extension of the full gallery is 120 meters, both horizontally and vertically, and the discretization is performed with a total of 29040 nodes and 7440 elements. The initial stresses and pore water pressure are imposed at the mesh external boundary. Assuming symmetry along the $\mathrm{x}$ - and $\mathrm{y}$-axes, only 
one quarter of the gallery can be discretised. In this case, the mesh extension is 60 meters, both horizontally and vertically, and the discretization is performed with a total of 9801 nodes and 2480 elements. The initial stresses and pore water pressure are also imposed at the mesh external boundary and both meshes have a more refined discretization close to the gallery. To establish the symmetry, the normal displacements and the water flow are blocked to a value of zero along the symmetry axes, that therefore are impervious. Nonetheless, as mentioned by Zervos et al (2001a), a special care must be brought to the kinematics boundary conditions required to establish the symmetry. Due to the existence of gradient terms in the equilibrium equations, higher order constraints have to be characterised in addition to the classical boundary condition on the normal displacements. This second kinematic condition requires that the radial displacement $u_{r}$ must be symmetric on both sides of the symmetry axes. This implies that the normal derivative of $u_{r}$, with respect to the tangential direction $\theta$, has to cancel :

$\frac{\partial u_{r}}{\partial \theta}=0$

which is equivalent to :

$x-\operatorname{axis}: \frac{\partial u_{x}}{\partial y}=0$

$y-\operatorname{axis}: \frac{\partial u_{y}}{\partial x}=0$

In order to correctly represent the fractures, the internal length scale inherent to the second gradient mechanical law has to be characterized. As mentioned in section 4.2, the internal length scale is related to the second gradient elastic parameter $D$ but the mesh is independent of it. The mesh independency has been illustrated by Collin et al (2006). However, to have a better numerical precision of the post localisation plastic behaviour inside the shear localisation band, it has been shown that at least three elements are required within the band. This is the case not only for second gradient model but also for other regularization techniques, such as gradient plasticity or non-local formulation. Finally, a value of $D=5000[N]$ is used (Table 1 ) in the modelling.

The gallery excavation can now be considered. It is executed in five days during which the total stresses and the pore water pressure at the gallery wall decrease from their initial values to the atmospheric pressure of $100[\mathrm{kPa}]$. Then, the calculation is extended to a thousand days under constant stress to highlight possible transient effects (Fig. 11).

To model the air ventilation inside the gallery, it is assumed that, at the gallery wall, the liquid water inside the rock is in equilibrium with the water vapour of the gallery air. This assumption derives from the fact that, inside a porous media, if both gaseous and liquid phases are considered in the pores, then both phases of the water, the water vapour and the liquid water, should be in equilibrium. The balance equation that expresses this equilibrium is Kelvin's law which gives the concentration of water vapour in the gas phase as :

$R H=\frac{p_{v}}{p_{v, 0}}=\exp \left(\frac{-p_{c} M_{v}}{R T \rho_{w}}\right)$

where $R H$ is the air relative humidity, $p_{v}$ is the partial pressure of water vapour, $p_{v, 0}$ is the pressure of saturated water vapour, $M_{v}$ is the molar mass of water vapour $M_{v}=$ $0.018[\mathrm{~kg} / \mathrm{mol}], R$ is the gas constant $R=8.314[\mathrm{~J} / \mathrm{molK}]$ and $T$ is the absolute temperature expressed in Kelvin. The air temperature is chosen based on Andra's measurements performed during an in situ ventilation experiment detailed in Cruchaudet et al (2010a). An average value of $25\left[{ }^{\circ} \mathrm{C}\right]$ $(T=298.15[K])$ is adopted.

Two cases are considered for the air inside the gallery (Fig. 11). In the first case, there is no ventilation inside the gallery, thus the air is saturated with water vapour and this maximum concentration corresponds to $R H=100$ [\%]. According to Kelvin's law, the corresponding pore water pressure at the gallery wall is the atmospheric pressure $p_{w}=$ $p_{g}=100[\mathrm{kPa}]$. The pore water pressure is then maintained constant after the end of the excavation and the claystone will remain almost saturated. In the second case, air ventilation is taken into account since ventilation is usually realised in the galleries composing underground structures. It may drain the water from the rock, desaturate it and modify the structure, the fracturing pattern as well as the size of the damaged zone. Air ventilation can thus be modelled in order to observe its effects on the rock material. The air which is injected in the gallery is dryer than previously and we consider a lower relative humidity of 80 [\%]. Following Eq. 59, this humidity corresponds to a pore water pressure at gallery wall of $p_{w}=-30.7[\mathrm{MPa}]$. To reach this value, the decrease of $p_{w}$ is performed in two steps : firstly, it decreases from its initial value to the atmospheric pressure during the excavation (5 days), and then, an initiation phase of ventilation is considered ( 5 days) to reach the final value. After this initiation phase, a constant ventilation is maintained. The imposed total stresses and pore water pressure evolution at the gallery wall are presented in Fig. 11 for the two considered cases. It is worth to mention that the ventilation effect on the fractures is therefore represented through the hydro-mechanical model. In fact, the ventilation influences the pore water pressures and the effective stresses, which then influence the shear strain localisation structure and behaviour.

The main purpose of this numerical modelling is to represent the fractures considering shear strain localisation and to reproduce, as well as possible, the in situ measurements and observations with an isotropic model. This type of modelling, especially at large repository scale and including desaturation of the clayey rock formation as well as solid grain 


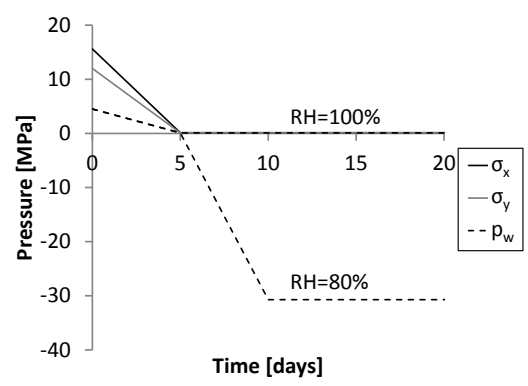

Fig. 11 Imposed total stresses and pore water pressure at the gallery wall, for the modelling of a gallery excavation with and without air ventilation

compressibility, has not been extensively performed nowadays. It constitutes the major novelty of this work.

\section{Results and discussion}

6.1 Influence of in situ stresses and permeability anisotropies

The damaged zone creation and evolution can be observed through the evolution of shear strain localisation. The latter is not a priori assured to be symmetric around the gallery and many solutions could emerge (Sieffert et al 2009). To avoid any early symmetry assumption, the excavation of a full gallery is firstly modelled in isotropic conditions assuming $\sigma_{x, 0}=\sigma_{y, 0}=\sigma_{z, 0}=15.6[\mathrm{MPa}]$ and $k_{x x}=k_{y y}=$ $4 \times 10^{-20}\left[\mathrm{~m}^{2}\right]$. The calculation is performed with $b=1$ and no ventilation. With a circular gallery and such isotropic state, it is not possible to trigger the shear strain localisation and the deformation remains diffuse as shown in Fig. 12(a). This figure presents the numerical results at the end of the excavation in term of Von Mises' equivalent deviatoric total strain $\varepsilon_{e q}=\sqrt{\frac{2}{3} \hat{\varepsilon}_{i j} \hat{\varepsilon}_{i j}}$, i.e. total deviatoric strain, and plastic zone, represented by the plastic loading mesh points. Strain localisation can be triggered through the introduction of an imperfection in the material as illustrated in Fig. 12(b). The imperfection consists of weaker elements with lower initial saturated cohesion $c_{0}=2[\mathrm{MPa}]$ that are located at the gallery wall.

However, in case of anisotropic stress state of the rock, $\sigma_{x, 0}=15.6[\mathrm{MPa}]$ and $\sigma_{y, 0}=\sigma_{z, 0}=12[\mathrm{MPa}]$, shear strain localisation appears without adding an imperfection in the rock. Fig. 13 illustrates the evolution of the strain localisation around the gallery, during and after the drilling. The numerical results that are presented are the deviatoric strain increment $\alpha=\frac{\dot{\varepsilon}_{e q} d t}{\int \dot{\varepsilon}_{e q} d t}$, the total deviatoric strain and the plastic zone. The modelling exhibits a symmetric chevron fracture pattern around the gallery similar to in situ observations (see Fig. 4 from Armand et al 2014; Cruchaudet et al 2010b). The chevron fractures appear during the excavation (a)
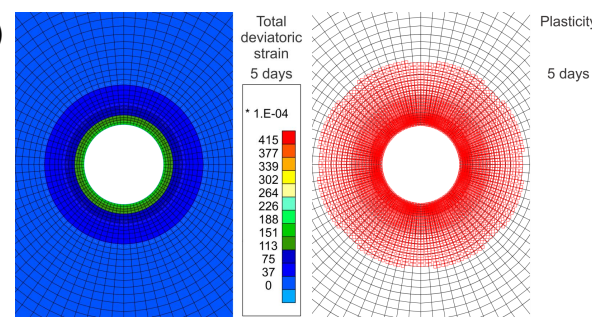

(b)

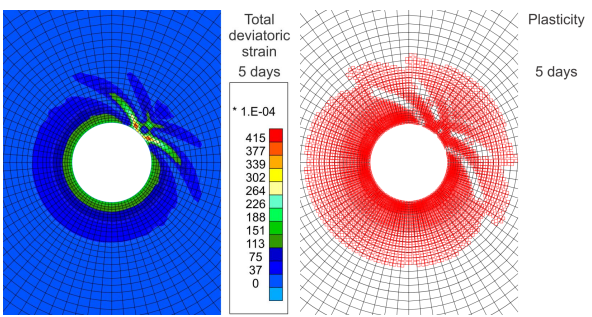

Fig. 12 Deformation and plasticity at the end of excavation, for a full gallery and an isotropic rock state : without material imperfection (a), with material imperfection (b)

and are mainly concentrated above the gallery because of the material anisotropic stress state. On the contrary, introducing only the anisotropy of the intrinsic water permeability, $k_{x x}=4 \times 10^{-20}\left[\mathrm{~m}^{2}\right]$ and $k_{y y}=1.33 \times 10^{-20}\left[\mathrm{~m}^{2}\right]$, does not lead to strain localisation unless an imperfection is introduced. It means that, the appearance and shape of the strain localisation are mainly due to mechanical effects, linked to the anisotropic stress state.

\subsection{Influence of second gradient boundary condition}

The previous modelling highlights that the anisotropic stress state of the Callovo-Oxfordian claystone is at the origin of a symmetry in the localisation pattern around the gallery. Then, it would be convenient, in the following, to consider only a quarter of a gallery. However, in the context of second gradient theory, a boundary condition of higher order should be considered in addition to the classical boundary condition of constrained displacement perpendicular to the boundary (Zervos et al 2001a). This second kinematic condition specifies that the normal derivative of the radial displacement has to cancel on the symmetry axes.

To illustrate the necessity of this second gradient boundary condition, we compare the strain localisation pattern of Fig. 13 to the one obtained on a quarter of a gallery. The modelling on a quarter of a gallery is computed with the specific second gradient boundary condition, and, as previously, with $b=1$ and no ventilation. In Fig. 14, we can observe that using the second gradient boundary condition produces a shear strain localisation pattern that is similar to the full-gallery results. Thus it is confirmed that, for calculation simplicity and symmetry reasons, a quarter of a gallery can be adopted for future modelling, provided that the specific second gradient boundary condition is used. 


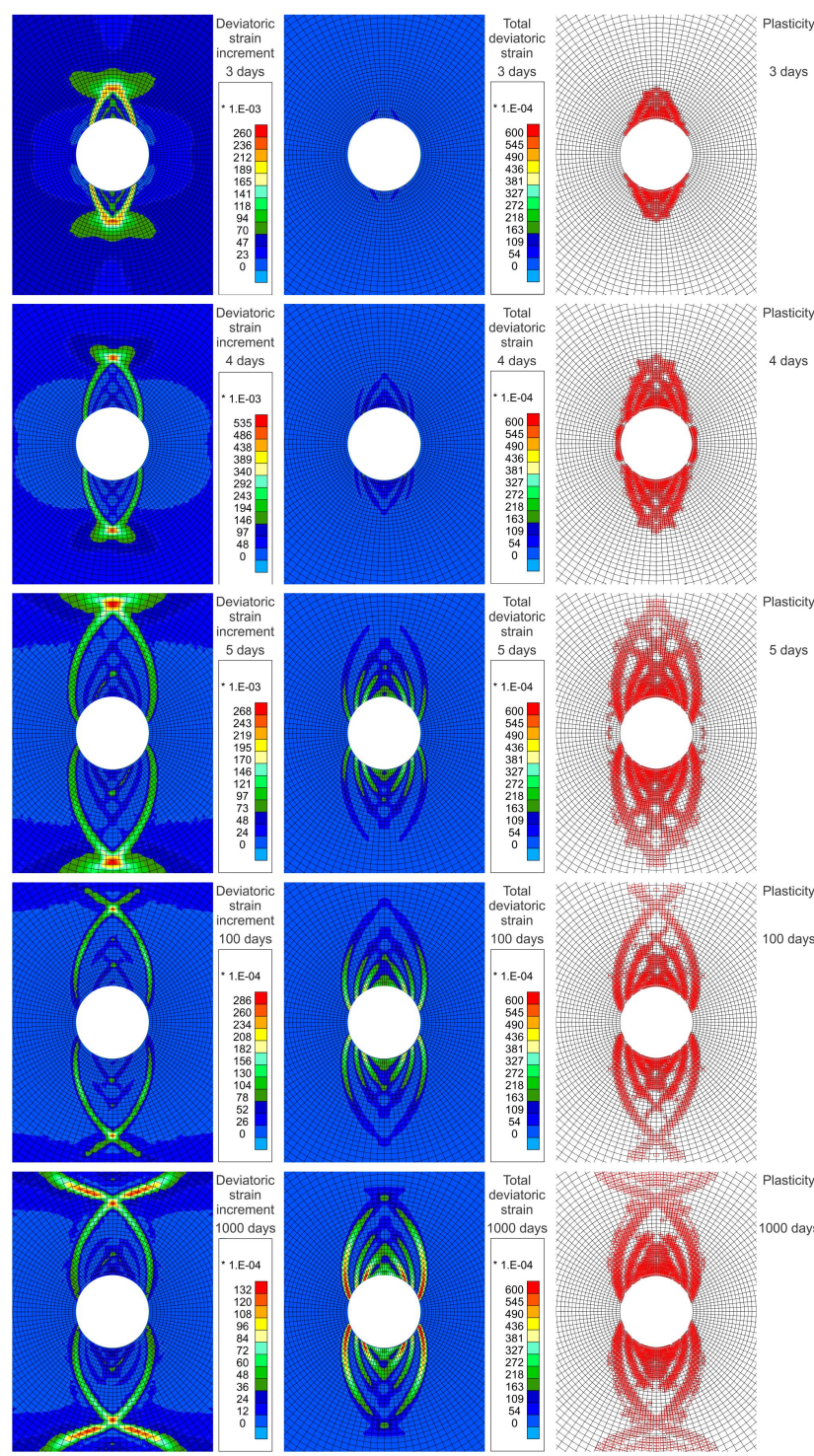

Fig. 13 Evolution of strain localisation during and after gallery excavation (5 days of excavation), for a full gallery and an anisotropic rock state

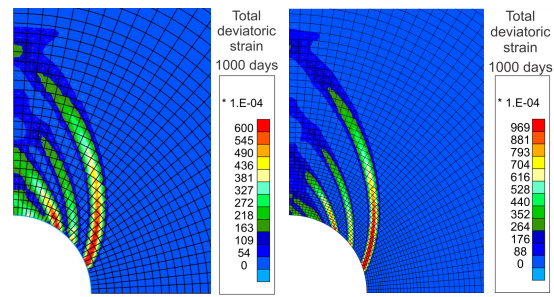

Fig. 14 Comparison of the strain localisation pattern at the end of the calculation, for the modelling of a full gallery (left) and of a quarter of a gallery with the second gradient boundary condition (right)

\subsection{Influence of Biot's coefficient}

Even if strain localisation seems to be mainly controlled by mechanical effects, hydraulic conditions can also impact the fracturing pattern. Here, we focus on the influence of Biot's coefficient for the case without ventilation. In the first calculation, we assume that the solid grain skeleton is incompressible, which implies $b=1$ (Fig. 15). In the second calculation, we use a value of $b=0.6$ which corresponds to the compressibility of solid grains commonly admitted for the Callovo-Oxfordian claystone (Fig. 16). Comparison of Fig. 15 and Fig. 16 indicates that the Biot's coefficient significantly influences the shear bands pattern. With a value of 0.6, less bands appear and the shear strain localisation is delayed. Matter of fact, the strain remains diffuse until the fourth day of the excavation, nonetheless the localisation appears before the end of the excavation. This can be explained by examining the stresses close to the gallery. At the gallery wall, the total stresses and the pore water pressure are imposed. Consequently, following Bishop's effective stress definition of Eq. 6, the lower the Biot's coefficient, the higher the effective stress at the gallery wall. This implies that the rock close to the gallery wall is more resistant and that the shear strain localisation appears later.

\subsection{Influence of gallery ventilation}

Let us now consider the modelling with the initial anisotropies, a Biot's coefficient value of 0.6 and the gallery ventilation. The drilling phase is not influenced by the ventilation, then the same results as in Fig. 16 are obtained until 5 days of computation. Nonetheless, the results obtained after the excavation, displayed in Fig. 17, indicate that the suction imposed at the wall strongly influences the results. Following Bishop's effective stress definition, the higher the suction, the higher the effective stress (Fig. 22). As noted before, this involves that the material is more resistant and, in this case, becomes elastic again close to the gallery. This inhibits the shear strain localisation around the gallery.

For this simulation, the extension of the EDZ in the rock, measured from the gallery wall up to the distance where strain localisation bands (total deviatoric strain) are observed, is detailed in Table 3. It is in a satisfactory agreement with the in situ experimental measurements of shear fractures from the GED gallery (Fig. 5), provided by Bordeau et al (2007) and Armand et al (2014)

Various numerical results, coming from the gallery wall and the rock mass, are interpreted hereafter in order to emphasize the influence of the gallery air ventilation. Results for selected cross-sections and observation points on the gallery wall are presented in Fig. 18. The results are compared for the cases considering $(R H=80[\%])$ or not $(R H=100[\%])$ the ventilation. 


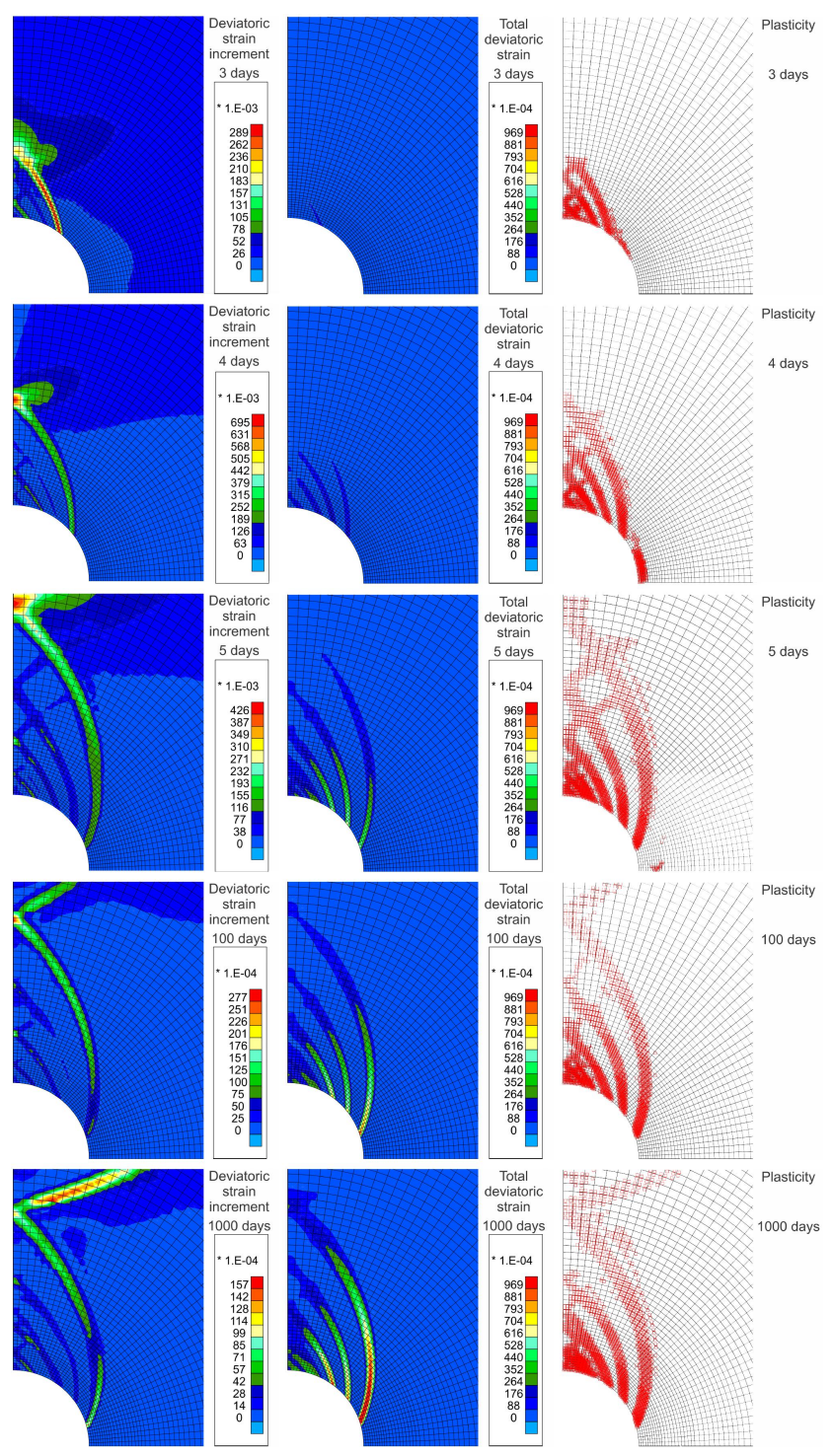

Fig. 15 Evolution of strain localisation during and after gallery excavation (5 days of excavation), without gallery ventilation and for a Biot's coefficient value of 1

Table 3 Comparison between the thickness of the numerical strain localisation zone and of the in situ observed fractured zone around a gallery from Cruchaudet et al (2010b)

\begin{tabular}{llll}
\hline Direction & $\begin{array}{l}\text { Numerical } \\
{[\mathrm{m}]}\end{array}$ & $\begin{array}{l}\text { In situ } \\
\text { mixed } \\
\text { fractures [m] }\end{array}$ & $\begin{array}{l}\text { In situ } \\
\text { shear } \\
\text { fractures [m] }\end{array}$ \\
\hline Horizontal & 0.5 & 0.5 & 0.8 \\
Vertical upward & 4.6 & 1.7 & 3.9 \\
Vertical downward & 4.6 & 2.0 & 5.1 \\
\hline
\end{tabular}

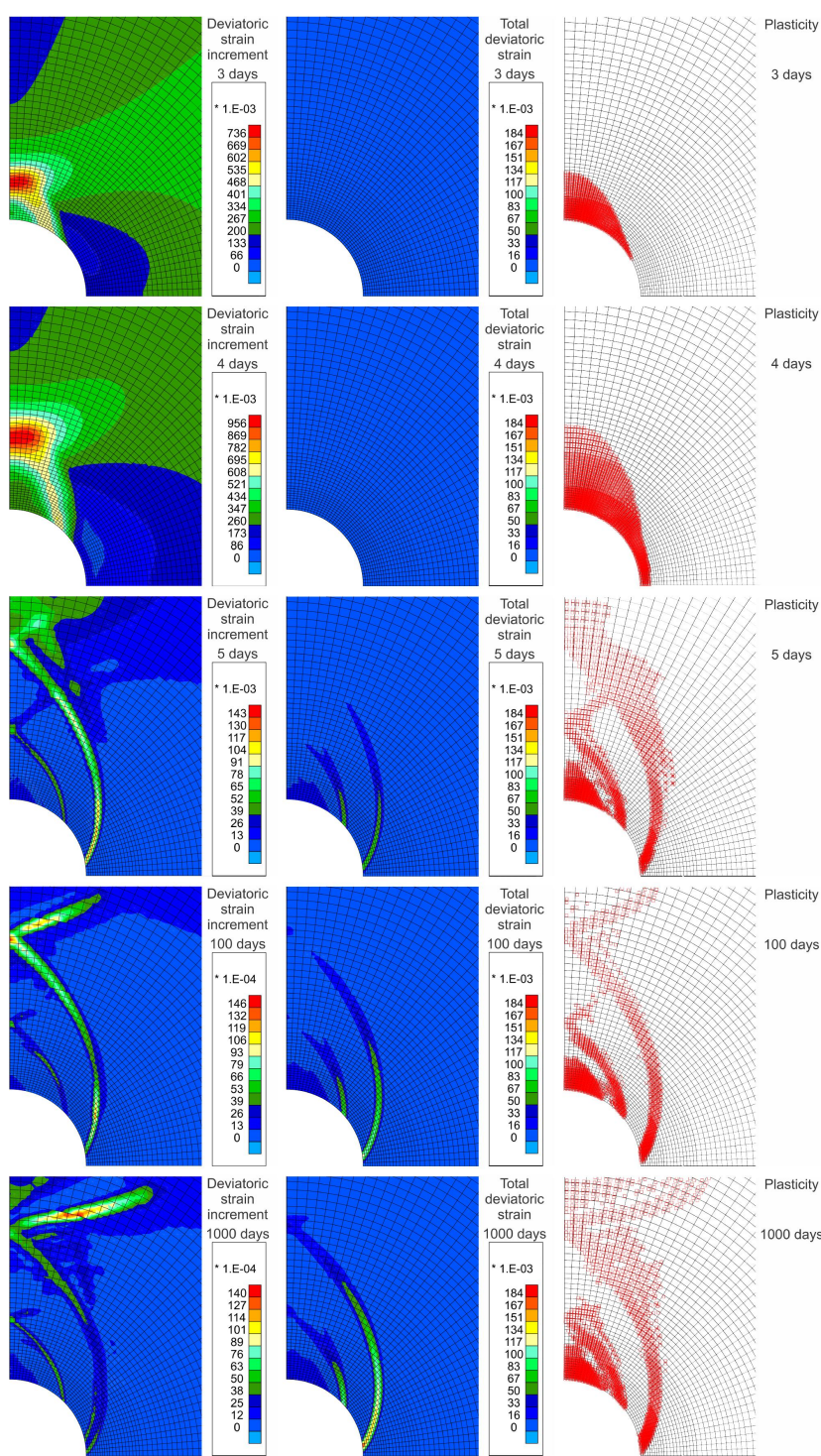

Fig. 16 Evolution of strain localisation during and after gallery excavation (5 days of excavation), without gallery ventilation and for a Biot's coefficient value of 0.6

Firstly, the evolution of pore water pressure for the vertical and horizontal cross-sections is detailed in Fig. 19. In the rock mass, we observe an increase of pressure in the vertical direction and a decrease in the horizontal direction up to a radial distance of about $30[\mathrm{~m}]$. The influence of the strain localisation bands, illustrated by the fluctuations of the pore water pressure in limited zones, is visible in the vertical direction. It can be mostly observed during the first 50 days of calculation, then it tends to vanish. This is due to the strain increment inside the bands (band activity) and the hydro-mechanical coupling. As expected, the influence of the ventilation is marked close to the gallery wall but tends to disappear deeper in the rock.

Secondly, the evolution of the water degree of saturation along the cross-sections is illustrated in Fig. 20. For the 


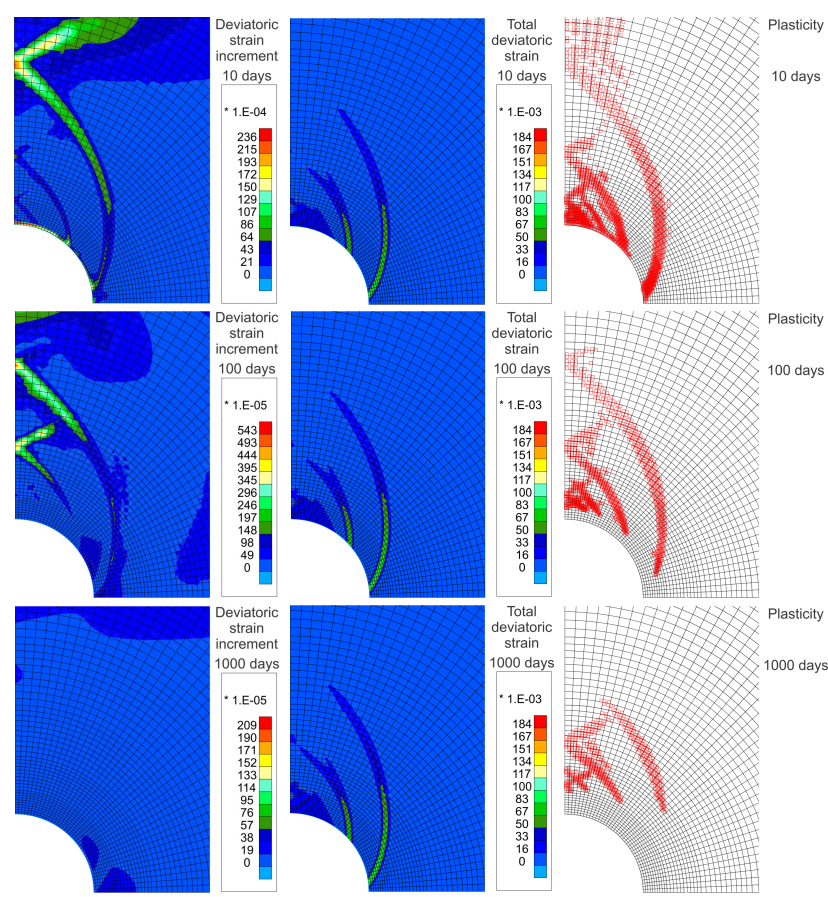

Fig. 17 Evolution of strain localisation after gallery excavation, with gallery ventilation and for a Biot's coefficient value of 0.6

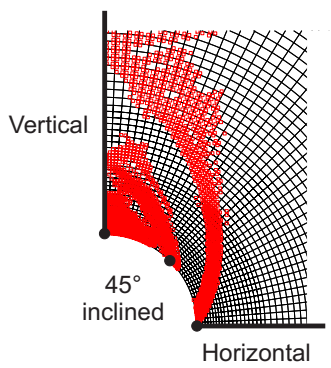

Fig. 18 Positions of cross-sections and gallery wall observation points
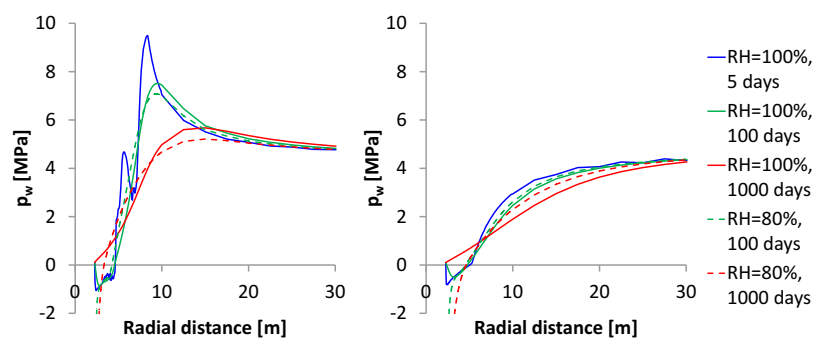

Fig. 19 Evolution of pore water pressure along vertical (left) and horizontal (right) cross-sections, after gallery excavation

modelling without ventilation, the influence of the strain localisation bands activity is also visible in the vertical direction, in the short term. Nevertheless, the claystone remains almost saturated at the gallery wall and fully saturated after a distance of $3[\mathrm{~m}]$ in the rock. For the modelling with ventilation, a strong desaturation is observed close to the wall. Fig. 21 illustrates the evolution of the water degree of satu-
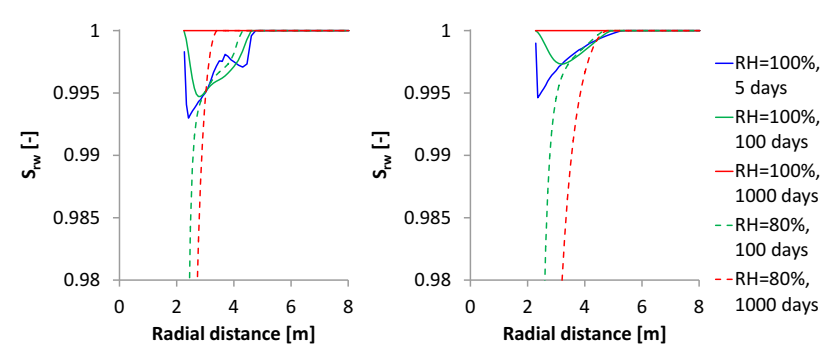

Fig. 20 Evolution of the water degree of saturation along vertical (left) and horizontal (right) cross-sections, after gallery excavation

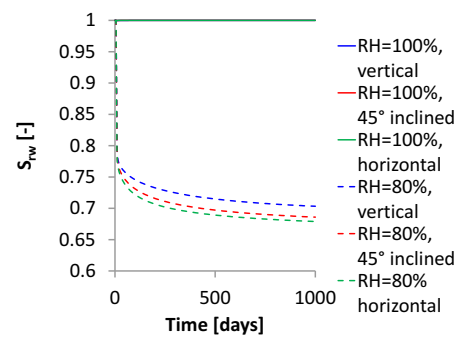

Fig. 21 Evolution of the water degree of saturation at the gallery wall, during and after gallery excavation

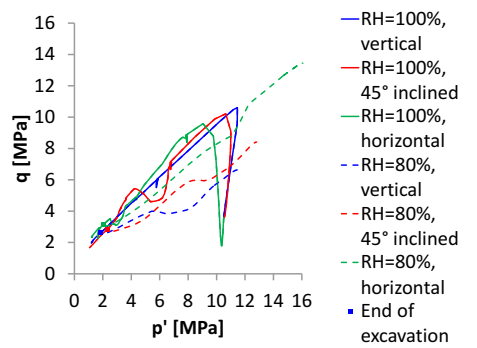

Fig. 22 Stress paths at the gallery wall, during and after gallery excavation

ration at the gallery wall and displays more clearly the desaturation.

Thirdly, the stress paths at the gallery wall are detailed in Fig. 22 where $q=\sqrt{3} I I_{\hat{\sigma}}$ is the deviatoric stress and $p^{\prime}=$ $\sigma^{\prime}=\sigma_{i i}^{\prime} / 3$ is Bishop's mean effective stress. As mentioned before, in case of ventilation the effective stresses are much higher due to the suction. This explains the difference between the stress paths of the modelling with or without ventilation, after the end of the drilling phase.

Fourthly, Fig. 23 illustrates the displacements evolution along the vertical and horizontal cross-sections. In the vertical direction, a strong influence of the strain localisation bands is observed close to the gallery, until the end of the calculation. Horizontally, the cross-section does not go through the localisation bands. For the modelling without ventilation, the displacements are important during the excavation and keep increasing afterwards, in both directions. When ventilation is applied, the displacements do not increase much after the excavation. This can also be observed in the evolution of the gallery convergence in Fig. 24 where a com- 

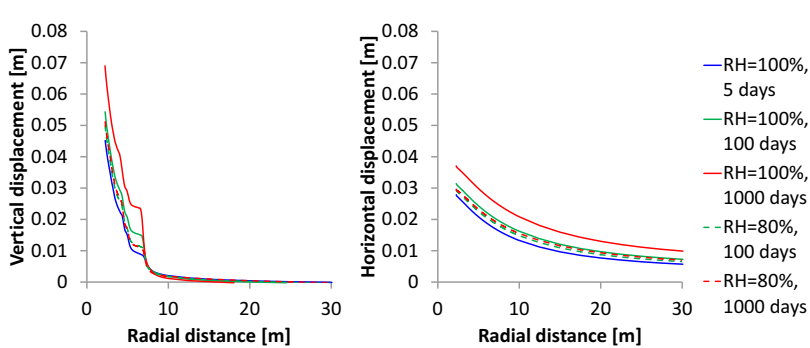

Fig. 23 Evolution of displacements along vertical (left) and horizontal (right) cross-sections, after gallery excavation
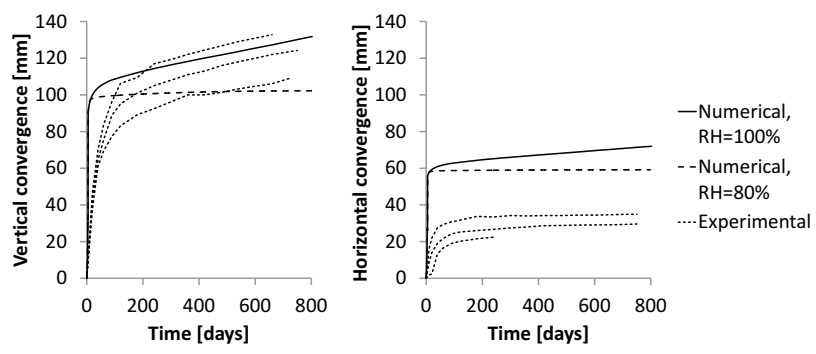

Fig. 24 Evolution of the vertical (left) and horizontal (right) convergences during and after gallery excavation, with comparison to experimental results from Cruchaudet et al (2010b)

parison with experimental results, from the same gallery of the Andra URL, is presented. These results come from measurement sections named OHZ120 A, B and C that are performed in the GED gallery (Cruchaudet et al 2010b). One can observe that vertical convergence is quite well captured by our model, on the contrary, horizontal convergence is still overestimated.

All these results put in evidence that noticeable differences exist whether ventilation is applied or not. For the modelling with ventilation, $p_{w}$ remains negative close to the gallery (Fig. 19), the effective stresses increase after the excavation (Fig. 22) and the material becomes elastic again. Consequently, the desaturation of the rock close to the gallery inhibits the shear strain localisation (Fig. 17) which has the effect of restricting the further deformation. On the contrary, without ventilation, $p_{w}$ close to the gallery wall increases after the excavation (Fig. 19), the effective stresses reduce (Fig. 22) and the material remains partly plastic close to the gallery (Fig. 16). This increases the deformation, and therefore the gallery convergence (Fig. 24).

Concerning the prediction of convergence in the short term, an anisotropy in a ratio of 3 is observed on in situ measurements of horizontal and vertical convergences (Fig. 24). If we study the problem with an isotropic model, without considering strain localisation but modelling the gallery ventilation, we correctly reproduce the horizontal convergence but not the vertical one (Fig. 25). Similar results are obtained by Plassart et al (2013). Therefore, this type of approach fails to reproduce the in situ measurements. In this work, we want to demonstrate that the fracturing and strain localisa-
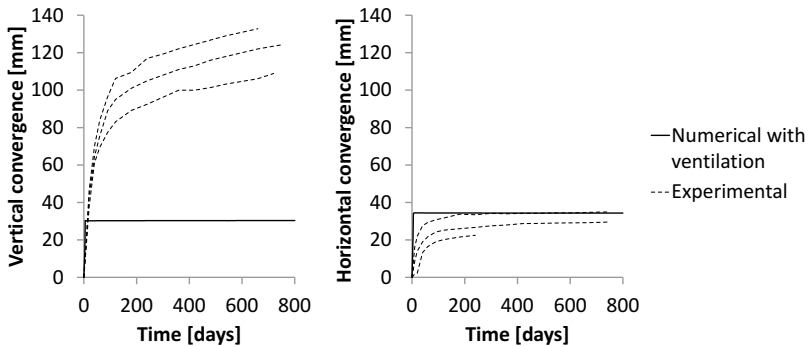

Fig. 25 Evolution of the vertical (left) and horizontal (right) convergences during and after gallery excavation, with comparison to experimental results from Cruchaudet et al (2010b), for a modelling without strain localisation and including gallery ventilation

tion processes permit to explain the convergence anisotropy. The fractures creation, globally above the gallery due to the material anisotropic stress state, indeed increases the vertical convergence but the horizontal one as well (Fig. 24). A good prediction of the vertical convergence is obtained but the horizontal one is overestimated. In that direction, the proximity of the shear band localisation induces excessive deformations. In the long term, the delayed deformations that are observed in situ can be explained by consolidation and creep effects. In contrast to this, when gallery ventilation is numerically performed, the material becomes elastic again close to the gallery wall and this phenomenon restricts plastic deformation and convergence in the long term.

Moreover, it is well known that the fracturing structure of the damaged zone varies when considering another initial stress state or another gallery direction for the considered host material (Armand et al 2014). The modelled gallery, drilled in the Callovo-Oxfordian claystone, is oriented in the direction of the minor horizontal principal stress, which leads to an anisotropic initial stress state. Since no other mechanical anisotropy is considered, this anisotropic initial stress state permits the appearance of shear strain localisation. Considering a gallery oriented parallel to the major horizontal principal stress would lead to a quasi-isotropic initial stress state (very low anisotropy). Unfortunately, this type of initial stress state does not permit the strain localisation appearance. In this case, the anisotropic rock behaviour should also be considered to model the fractures with shear bands but, as mentioned earlier, this is not the objective of this study.

To summarise, the modelling results of shear bands pattern and its extension correspond fairly well to fracture observations and measurements. The convergence is well reproduced in the vertical direction. The shape of the chevron fractures, the anisotropy of the convergence and the differences between results in the horizontal and vertical directions can be well explained by the material anisotropic stress state as well as by the strain localisation bands. Furthermore, even if important changes occur during the drilling, transient 
effects are observed after it. The influences of gallery ventilation as well as of the strain localisation bands on the displacements, pore water pressures and degree of saturation are highlighted.

To further improve the modelling, the anisotropic and viscoplastic behaviour of the material could be taken into account. The anisotropic behaviour would permit to improve the convergence. For instance, the Callovo-Oxfordian claystone has a horizontal Young's modulus higher than the vertical one, which would reduce the horizontal convergence. Time-dependent effects, such as viscoplasticity, would allow to improve the long-term behaviour of the material and to reproduce the convergence when gallery ventilation is performed. Nonetheless, the objective of this study is not to perform numerical modelling including viscoplastic and anisotropic aspects of the material behaviour. It is to investigate how accurately we can reproduce the in situ measurements and observations with an isotropic model but incorporating the fracture modelling with strain localisation.

\section{Conclusion and outlooks}

Following fracturing evidences, the second gradient theory is used to properly model the fractures around galleries, with strain localisation in shear band mode. The theory is successfully extended to multiphasic porous media under unsaturated conditions and the solid grain compressibility is taken into account through the Biot's coefficient. By using the second gradient model, the excavation damaged zone around a gallery in claystone is fairly well reproduced. Within this zone, the modelling provides information about the fracture structure and its evolution that are in very good agreement with in situ observations and measurements. Matter of fact, fracturing represented by strain localisation bands develops during the gallery excavation and the modelling exhibits a chevron fracture pattern around the gallery. The impacts of shear strain localisation bands and gallery ventilation on pore water pressures, degree of saturation and displacements are also highlighted. Regarding the influence of the gallery ventilation, a significant desaturation is observed close to the gallery wall and tends to disappear deeper in the rock mass, where the claystone remains fully saturated. Moreover, the gallery convergence is well reproduced with its anisotropy, its long-term evolution and the influence of the rock desaturation. The anisotropic convergence is related to the material anisotropic stress state and to the strain localisation bands. Despite the good reproduction of the vertical convergence, the horizontal one has still to be improved, which leads to the need of a better definition of the rock anisotropy.

Furthermore, despite the fact that the modelling provide information about the rock structure within the damaged zone, the rock state and its properties changes still need to be improved. Characterising the influence of the rock fracturing or damage on the mechanical and hydraulic properties remains a major issue. Following Levasseur et al (2009) recommendations, it would be necessary to develop a more accurate modelling of the rock anisotropy and of the hydromechanical coupling that occurs in the damaged zone. Different ways are possible to introduce the structural inherent anisotropy of argillaceous rock in the mechanical constitutive model, and to coupled it to localisation approach. Among others, we could consider the fabric tensor concept, which introduces a second order tensor describing the spatial distribution of the strength parameters, as proposed in homogeneous problems by Chen (2009), Chen et al (2010), Pietruszczak and Pande (2001) and Pietruszczak et al (2002). Concerning the hydro-mechanical coupling, it is known that permeability is not homogeneous in the damaged zone. One way to model it could be to introduce a permeability modification in the localisation bands by considering a dependency with a mechanical parameter, such as strain or plastic deformation by extension of Levasseur et al (2010) or Olivella and Alonso (2008) models.

Acknowledgements The authors would like to thank the Andra for the availability of the results of experimental measurements performed in its URL and the FRIA-F.R.S.-FNRS, the National Funds of Scientific Research in Belgium, for their financial support.

\section{References}

Aifantis EC (1984) On the microstructural origin of certain inelastic models. J Eng Mater Technol 106(4):326-330

Alshibli K, Batiste S, Sture S (2003) Strain Localization in Sand: Plane Strain versus Triaxial Compression. J Geotech Geoenviron Eng 129(6):483-494

Andra (2005) Dossier 2005 Argile. Synthesis: Evaluation of the Feasibility of a Geological Repository in an Argillaceous Formation, Meuse/Haute Marne site. Tech. rep., Paris, France

Armand G, Wileveau Y, Delay J (2007) Analyse des perméabilités mesurées autour des ouvrages du LSMHM au niveau $-490 \mathrm{~m}$ pour déterminer des lois empiriques utilisables dans des calculs hydromécaniques couplés en milieu continu. Tech. Rep. D.NT.ALS.07.0453, Andra

Armand G, Leveau F, Nussbaum C, de La Vaissiere R, Noiret A, Jaeggi D, Landrein P, Righini C (2014) Geometry and properties of the excavation-induced fractures at the Meuse/Haute-Marne URL drifts. Rock Mech Rock Eng 47(1):21-41

Barnichon JD (1998) Finite Element Modelling in Structural and Petroleum Geology. PhD thesis, Faculté des Sciences Appliquées, Université de Liège, Belgium

Bazant ZP, Belytschko TB, Chang TP (1984) Continuum Theory for Strain Softening. J Eng Mech 110(12):1666-1692

Bäckblom G (1991) The Äspö Hard Rock Laboratory-a step toward the Swedish final repository for high-level radioactive waste. Tunn Undergr Sp Tech 6(4):463-467

Behlau J, Mingerzahn G (2001) Geological and tectonic investigations in the former Morsleben salt mine (Germany) as a basis for the safety assessment of a radioactive waste repository. Eng Geol 61(2-3):83-97 
Blümling P, Bernier F, Lebon P, Martin CD (2007) The excavation damaged zone in clay formations time-dependent behaviour and influence on performance assessment. Phys Chem Earth 32(814):588-599

Bordeau F, Dedeckerv C, Billaux D (2007) Discrete modelling of drift behaviour in the meuse/haute-marne url (france). In: Clays in natural and engineered barriers for radioactive waste confinement, International Meeting, Lille, France

de Borst R, Mühlhaus HB (1992) Gradient-dependent plasticity: Formulation and algorithm aspects. Int J Numer Meth Eng 35(3):521539

Bossart P, Meier PM, Moeri A, Trick T, Mayor JC (2002) Geological and hydraulic characterisation of the excavation disturbed zone in the Opalinus Clay of the Mont Terri Rock Laboratory. Eng Geol 66(1-2):19-38

Bésuelle P, Chambon R, Collin F (2006) Switching deformation modes in post-localization solutions with a quasibrittle material. J Mech Mater Struct 1(7):1115-1134

Chambon R, Moullet JC (2004) Uniqueness studies in boundary value problems involving some second gradient models. Comput Methods Appl Mech Engrg 193(27-29):2771-2796

Chambon R, Caillerie D, Hassan NE (1998) One-dimensional localisation studied with a second grade model. Eur J Mech A-Solid 17(4):637-656

Chambon R, Caillerie D, Matsushima T (2001) Plastic continuum with microstructure, local second gradient theories for geomaterials : localization studies. Int J Solids Struct 38(46-47):8503-8527

Charlier R (1987) Approche unifiée de quelques problèmes non linéaires de mécanique des milieux continus par la méthode des éléments finis (grandes déformations des métaux et des sols, contact unilatéral de solides, conduction thermique et écoulements en milieu poreux). PhD thesis, Faculté des Sciences Appliquées, Université de Liège, Belgium

Charlier R, Collin F, Pardoen B, Talandier J, Radu JP, Gerard P (2013) An unsaturated hydro-mechanical modelling of two in-situ experiments in Callovo-Oxfordian argillite. Eng Geol 165:46-63

Chen L (2009) Contribution à la modélisation du comportement hydromécanique des géomatériaux semi-fragiles. $\mathrm{PhD}$ thesis, Université des Sciences et Technologies de Lille, Lille

Chen L, Shao JF, Huang HW (2010) Coupled elastoplastic damage modeling of anisotropic rocks. Comput Geotech 37(1-2):187-194

Collin F (2003) Couplages thermo-hydro-mécaniques dans les sols et les roches tendres partiellement saturés. PhD thesis, Faculté des Sciences Appliquées, Université de Liège, Belgium

Collin F, Chambon R, Charlier R (2006) A finite element method for poro mechanical modelling of geotechnical problems using local second gradient models. Int J Numer Meth Eng 65(11):1749-1772

Collin F, Levasseur S, Chambon R (2009) Numerical post failure methods in multiphysical problems. Eur J Environ Civ Eng 13(78):983-1004

Cosserat E, Cosserat F (1909) Théorie des Corps Déformables. Hermann, Paris

Coussy O (2004) Poromechanics. John Wiley, New York

Croisé J, Schlickenrieder L, Marschall P, Boisson JY, Vogel P, Yamamoto S (2004) Hydrogeological investigations in a low permeability claystone formation: the Mont Terri Rock Laboratory. Phys Chem Earth 29(1):3-15

Cruchaudet M, Noiret A, Talandier J, Armand G (2010a) Expérimentation SDZ - Bilan de la mise en place de l'instrumentation et des premières mesures à fin mars 2010 - Centre de Meuse/HauteMarne. Tech. Rep. D.RP.AMFS.09.0087, Andra

Cruchaudet M, Noiret A, Talandier J, Gatmiri B, Armand G (2010b) OHZ en GED: EDZ initiale et évolution. Tech. Rep. D.RP.AMFS.11.0016, Andra

Delage P, Howat MD, Cui YJ (1998) The relationship between suction and swelling properties in a heavily compacted unsaturated clay.
Eng Geol 50(1-2):31-48

Delay J, Vinsot A, Krieguer JM, Rebours H, Armand G (2007) Making of the underground scientific experimental programme at the Meuse/Haute-Marne underground research laboratory, North Eastern France. Phys Chem Earth 32(1-7):2-18

Desrues J (2005) Hydro-mechanical coupling and strain localization in saturated porous media. Rev Eur Génie Civ 9(5-6):619-634

Desrues J, Viggiani G (2004) Strain localization in sand: an overview of the experimental results obtained in Grenoble using stereophotogrammetry. Int J Numer Anal Met 28(4):279-321

Detournay E, Cheng AHD (1993) Comprehensive Rock Engineering: Principles, Practice and Projects, vol 2 Analysis and Design Method, Pergamon Press, Oxford, chap 5 Fundamentals of Poroelasticity, pp 113-171

Diederichs MS (2003) Rock Fracture and Collapse Under Low Confinement Conditions. Rock Mech Rock Eng 36(5):339-381

Emsley S, Olsson O, Stenberg L, Alheid HJ, Falls S (1997) ZEDEX: A Study of Damage and Disturbance from Tunnel Excavation by Blasting and Tunnel Boring. Svensk Kärnbränslehantering $\mathrm{AB} /$ Swedish Nuclear Fuel and Waste Management Co.

Finno R, Harris W, Mooney M, Viggiani G (1996) Strain localization and undrained steady state of sands. J Geotech Eng-ASCE 122(6):462-473

Finno R, Harris W, Mooney M, Viggiani G (1997) Shear bands in plane strain compression of loose sand. Géotechnique 47(1):149-165

Félix B, Lebon P, Miguez R, Plas F (1996) A review of the ANDRA's research programmes on the thermo-hydromechanical behavior of clay in connection with the radioactive waste disposal project in deep geological formations. Eng Geol 41(1-4):35-50

Gens A, Garcia-Molina AJ, Olivella S, Alonso EE, Huertas F (1998) Analysis of a full scale in situ test simulating repository conditions. Int J Numer Anal Met 22(7):515-548

van Genuchten MT (1980) A closed-form equation for predicting the hydraulic conductivity of unsaturated soils. Soil Sci Soc Am J 44(5):892-898

Gerard P, Léonard A, Masekanya JP, Charlier R, Collin F (2010) Study of the soil-atmosphere moisture exchanges through convective drying tests in non-isothermal conditions. Int J Numer Anal Meth Geomech 34(12):1297-1320

Germain P (1973) The method of virtual power in continuum mechanics. Part 2 Microstructure. SIAM J Appl Math 25(3):556-575

Han C, Drescher A (1993) Shear bands in biaxial tests on dry coarse sand. Soils Found 33(1):118-132

Jenq YS, Shah SP (1988) Mixed-mode fracture of concrete. Int J Fracture 38(2):123-142

Kickmaier W, McKinley I (1997) A review of research carried out in European rock laboratories. Nucl Eng Des 176(1-2):75-81

Kotronis P, Collin F, Bésuelle P, Chambon R, Mazars J (2007) Local Second Gradient Models and Damage Mechanics: 1D PostLocalization Studies in Concrete Specimens. In: Exadaktylos G, Vardoulakis I (eds) Bifurcation, Instabilities and Degradation in Geomechanics, Springer, pp 127-142

Langer M (1999) Principles of geomechanical safety assessment for radioactive waste disposal in salt structures. Eng Geol 52(3-4):257269

Lenoir N, Bornert M, Desrues J, Bésuelle P, Viggiani G (2007) Volumetric digital image correlation applied to X-ray microtomography images from triaxial compression tests on argillaceous rock. Strain 43(3):193-205

Levasseur S, Bésuelle P, Collin F, Chambon R, Charlier R, Viggiani C (2009) EDZ in clayey rocks: which effect on permeability? In: Li X, Jing L, Blaser P (eds) Impact of thermo-hydro-mechanicalchemical (THMC) processes on the safety of underground radioactive waste repositories. Proceedings of the European Commission TIMODAZ-THERESA International Conference, European Commission, Luxembourg, pp 173-183 
Levasseur S, Charlier R, Frieg B, Collin F (2010) Hydro-mechanical modelling of the excavation damaged zone around an underground excavation at Mont Terri Rock Laboratory. Int J Rock Mech Min 47(3):414-425

Léonard A, Blacher S, Marchot P, Crine M (2002) Use of X-ray microtomography to follow the convective heat drying of wastewater sludges. Dry Technol 20(4-5):1053-1069

Léonard A, Blacher S, Marchot P, Pirard JP, Crine M (2003) Image analysis of X-ray microtomograms of soft materials during convective drying. J Microsc 212(Pt2):197-204

Léonard A, Blacher S, Marchot P, Pirard J, Crine M (2005) Convective drying of wastewater sludges: Influence of air temperature, superficial velocity and humidity on the kinetics. Dry Technol 23(8):1667-1679

Matray JM, Savoye S, Cabrera J (2007) Desaturation and structure relationships around drifts excavated in the well-compacted Tournemire's argillite (Aveyron, France). Eng Geol 90(1-2):1-16

Mayor JC, Velasco M, García-Siñeriz JL (2007) Ventilation experiment in the Mont Terri underground laboratory. Phys Chem Earth 32(814):616-628

Mindlin RD (1964) Micro-structure in linear elasticity. Arch Ration Mech An 16(1):51-78

Mindlin RD (1965) Second gradient of strain and surface-tension in linear elasticity. Int J Solids Struct 1:417-438

Mokni M, Desrues J (1999) Strain localisation measurements in undrained plane-strain biaxial test on Hostun RF sand. Mech Cohes-Frict Mat 4(4):419-441

Neerdael B, Boyazis JP (1997) The Belgium underground research facility: Status on the demonstration issues for radioactive waste disposal in clay. Nucl Eng Des 176(1-2):89-96

Nuth M, Laloui L (2008) Effective stress concept in unsaturated soils: Clarification and validation of a unified framework. Int J Numer Anal Met 32(7):771-801

Olivella S, Alonso EE (2008) Gas flow through clay barriers. Géotechnique 58(3):157-176

Peerlings RHJ, de Borst R, Brekelmans WAM, de Vree JHP (1996a) Gradient-enhanced damage for quasi-brittle materials. Int J Numer Meth Eng 39:3391-3403

Peerlings RHJ, de Borst R, Brekelmans WAM, de Vree JHP, Spee I (1996b) Some observations on localisation in non-local and gradient damage models. Eur J Mech A/Solids 15(6):937-953

Peron H, Hueckel T, Laloui L, Hu LB (2009a) Fundamentals of desiccation cracking of fine-grained soils: experimental characterisation and mechanisms identification. Can Geotech J 46(10):1177-1201

Peron H, Laloui L, Hueckel T, Liang BH (2009b) Desiccation cracking of soils. Eur J Environ Civ Eng 13(7-8):869-888

Pietruszczak ST, Mróz Z (1981) Finite element analysis of deformation of strain-softening materials. Int J Numer Meth Eng 17(3):327334

Pietruszczak ST, Pande GN (2001) Description of soil anisotropy based on multi-laminate framework. Int J Numer Anal Meth Geomech 25(2):197-206

Pietruszczak ST, Lydzba D, Shao JF (2002) Modelling of inherent anisotropy in sedimentary rocks. Int J Solids Struct 39(3):637-648

Pijaudier-Cabot G, Bazant ZP (1987) Nonlocal damage theory. J Eng Mech 113(10):1512-1533

Plassart R, Fernandes R, Giraud A, Hoxha D, Laigle F (2013) Hydromechanical modelling of an excavation in an underground research laboratory with an elastoviscoplastic behaviour law and regularization by second gradient of dilation. Int J Rock Mech Min 58:23-33

Romero E, Gens A, Lloret A (2001) Temperature effects on the hydraulic behaviour of an unsaturated clay. Geotech Geol Eng 19(34):311-332

Sieffert Y, Holo SA, Chambon R (2009) Loss of uniqueness of numerical solutions of the borehole problem modelled with enhanced media. Int J Solids Struct 46(2):3173-3197

Ta AN (2009) Etude de l'interaction sol-atmosphère en chambre environnementale. $\mathrm{PhD}$ thesis, Ecole Nationale des Ponts et Chaussées, Paris

Toupin R (1962) Elastic materials with couple-stresses. Arch Ration Mech An 11(1):385-414

Tsang CF, Bernier F (2004) Definitions of excavation disturbed zone and excavation damaged zone, in Impact of the excavation disturbed or damaged zone (EDZ) on the performance of radioactive waste geological repositories. In: Proceedings European Commission CLUSTER Conference and Workshop on EDZ in Radioactive Waste Geological Repositories, Luxembourg

Tsang CF, Bernier F, Davies C (2005) Geohydromechanical processes in the Excavation Damaged Zone in crystalline rock, rock salt, and indurated and plastic clays - in the context of radioactive waste disposal. Int J Rock Mech Min 42(1):109-125

Vardoulakis I, Goldscheider M, Gudehus Q (1978) Formation of shear bands in sand bodies as a bifurcation problem. Int J Numer Anal Met 2(2):99-128

Wileveau Y, Cornet FH, Desroches J, Blumling P (2007) Complete in situ stress determination in an argillite sedimentary formation. Phys Chem Earth 32(8-14):866-878

Wu S, Wang X (2010) Mesh Dependence and Nonlocal Regularization of One-Dimensional Strain Softening Plasticity. J Eng Mech 136(11):1354-1365

Young JF (1967) Humidity control in the laboratory using salt solutions-a review. J Appl Chem 17(9):241-245

Zervos A, Papanastasiou P, Vardoulakis I (2001a) Modelling of localisation and scale effect in thick-walled cylinders with gradient elastoplasticity. Int J Solids Struct 38(30-31):5081-5095

Zervos A, Papanastasious P, Vardoulakis I (2001b) A finite element displacement formulation for gradient elastoplasticity. Int J Numer Meth Eng 50(6):1369-1388

Zhang F, Jia Y, Bian HB, Duveau G (2013) Modeling the influence of water content on the mechanical behavior of callovo?oxfordian argillite. Phys Chem Earth 65:79-89 